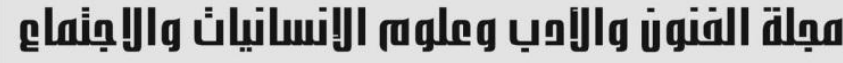

Journal of Arts, Literature, Humanities and Social Sciences www.jalhss.com

\title{
أثر طريقة نقد آليت آيزنر في تنمية مهارات التذوق الفني لاى طالبات المرحلة المتوسطة
}

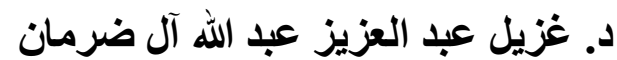
أستاذ التربية الفنية المساعد بكلية التربية بالالم - جامعة الأمير سطام بن عبد العزيز بالخرج ـ المملكة العربية

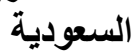
البريد الاكتروني: g.aldhorman@psau.edu.sa

الماخص

هدف البحث الحالي إلى التعرف على آثر طريقة نقد آليت آيزنر في تنمية مهار ات التذوق الفني لدى طالبات المرحلة المتوسطة بالرياض، التعرف على الفروق في مهار ات التذوق الفني لدى طالبات المرحلة المتوسطة. كما هدف إلى تفسير مفهوم الأبعاد الستة في طريقة نقد آليت آيزنر لطالبات المرحلة المتوسطة. وبنـاء مقياس لتحليل الأبعاد الستة في طريقة نقد آليت آيزنر عند قراءة الأعمال الفنية. وتكونت عينة الدر اسة من (72) طالبة من مدارس الرياض، تمثلت في مجمو عتين متكافئتين همـا المجموعـة الضابطة و المجمو عة التجريبية، كل مجمو عة مكونة من (34) طالبة. وتم اختيار هن بطرقة قصدية. و اشتملت أدوات البحث على اختبار قبلي واختبار بعدي، كما اشتملت على مقياس لتحليـل الأبعاد الستة في طريقة نقد آليت آيزنر عند قر اعة الأعمـال الفنيـة من إعداد الباحثة، يمكن من خلالله تقييم إجابـات الطالبـات في الاختبار القبلي و البعدي، وبعد التأكد من الخصائص السيكو منرية (الصدق و الثبات)، ومعالجة البيانـات احصـائيا على برنـامج (spss)، تم التطبيق على عينـة البحث باتبـاع المنهج الوصفي التحليلي، و المنهج شبه التجرييهي. وتوصـلت النتـائج إلى وجـود فروق دالـة إحصـائيا بين متوسط درجـات المجمـوعتين التجريبيـة و الضـابطة في التطبيق البعدي لاختبار النقد الفني لصالح المجموعة التجريبية. ووجود فروق دالة إحصسائيا بين متوسط درجات المجمو عة التجريبية في التطبيق القبلي والتطبيق البعدي لاختبار النقد الفني لصالح التطبيق البعدي. 


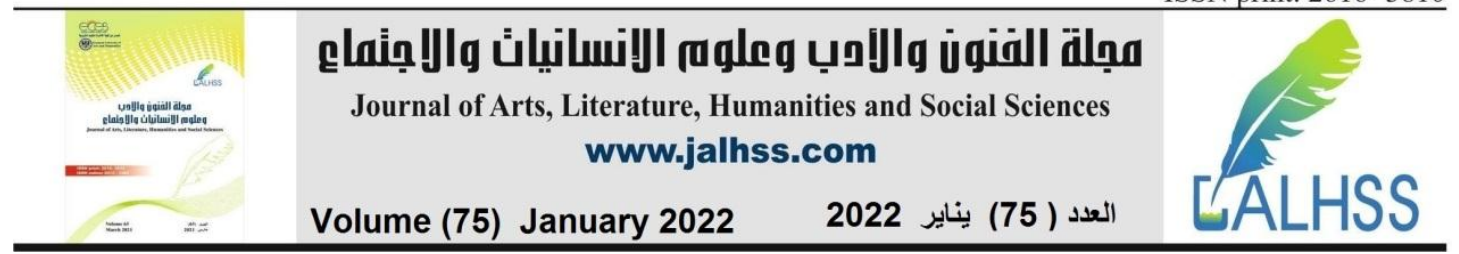

\title{
The Effect of the Elliot Eisner Criticism Method in Developing the art Appreciation Skills among Intermediate School Students
}

\author{
Dr. Ghazeail Abdul Aziz Abdullah Al Dhorman \\ Assistant Professor of Art Education - Faculty of Education in Al-Dilam - Prince Sattam \\ Bin Abdulaziz University -Kingdom of Saudi Arabia \\ Email: aldhorman@psau.edu.sa
}

\begin{abstract}
The current research aims to identify the effect of the Eisner mechanism's criticism method in developing the art appreciation skills among intermediate students in Riyadh and to identify the differences of the art appreciation skills among intermediate students. It also aimed to explain the concept of the six dimensions in the Elliot Eisner criticism method among intermediate students and build a scale to analyze the six dimensions in the Elliot Eisner criticism method when reading artworks.

The study sample consisted of (72) female students from Riyadh schools, represented in two equal groups, the control group and the experimental group, each group consisting of (34) female students. They were chosen intentionally.

The research tools included a pre-test and a post-test, as well as a scale for analyzing the six dimensions in the Elliot Eisner criticism method when reading artwork prepared by the researcher, through which it is possible to evaluate the students' answers in the pre-and posttest, and after verifying the psychometric properties (validity and stability) and data processing statistically on the program (SPSS), It was applied to the research sample by following the descriptive-analytical method, and the semi-experimental method. The results showed that there were statistically significant differences between the average scores of the experimental and control groups in the post-application of the art criticism scale in favor of the experimental group. And there are statistically significant differences between the mean scores of the experimental group in the pre and post-application of the art criticism scale in favor of the post-application.
\end{abstract}

Keywords: Elliot Eisner, art criticism, art appreciation, intermediate school. 


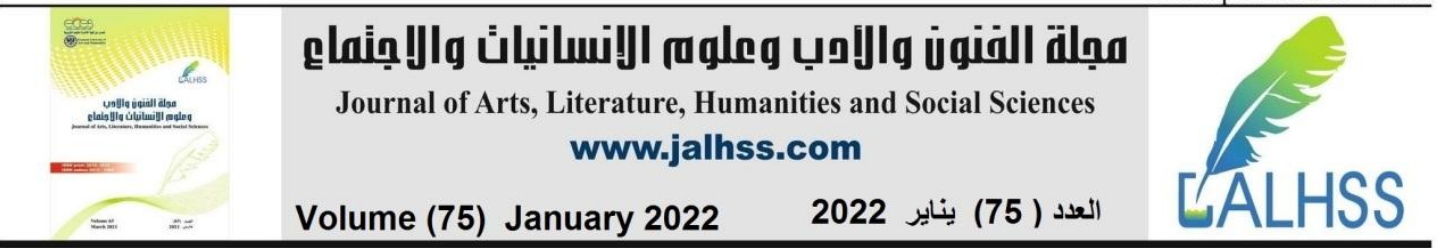

المقدمة:

تعد ابتكار الأساليب الجديدة في خدمة المتعلمين وتوظيفها معرفيا ومهاريا لهم، من سمات معلم التربيـة الفنيـة

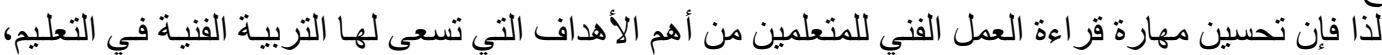

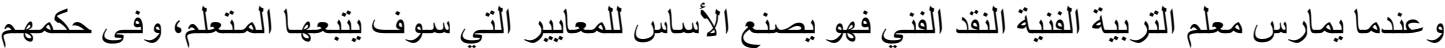

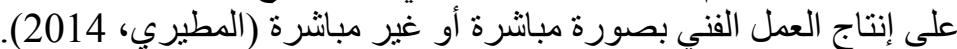

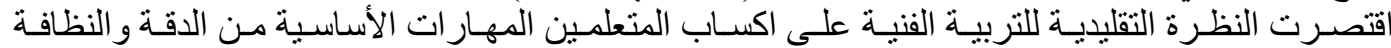

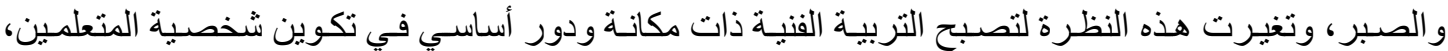

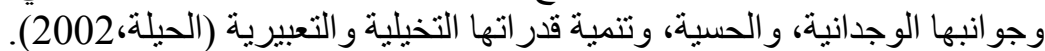

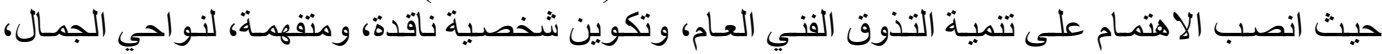

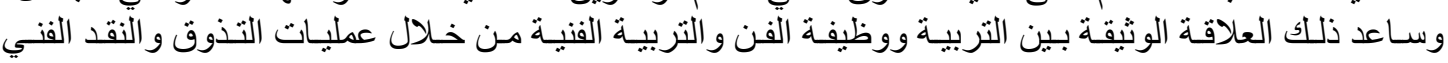

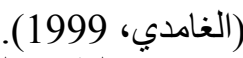
ورن الطرق الصحيحة في نقد وتحليل الأعمال الفنية الطريقة الموضو عية من خلال المناقتة التي تتم داخل

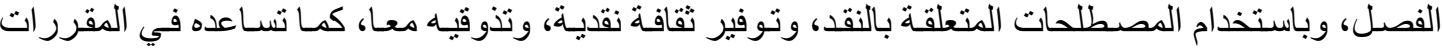

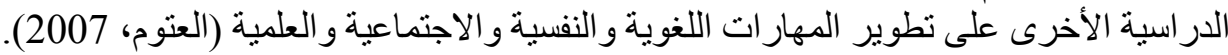

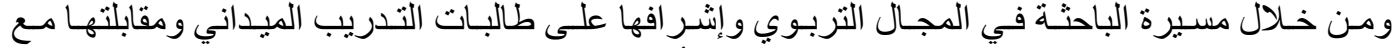
المشرفات التربويات والمعلمات لاحظت قصور في تحقيق أهداف التربيـة الفنية كمنهج، خاصـة في في النقد الفني

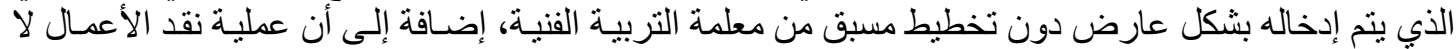

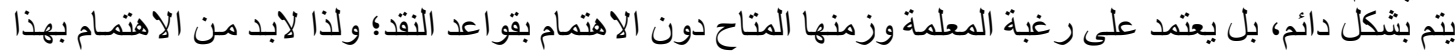
الجانب حيث يعتبر النقد الفني الأساس الثاني الذي تقوم عليه النظرية المبنية على أن الفن مادة درية دراسية.

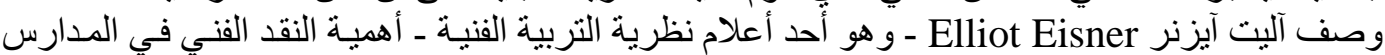

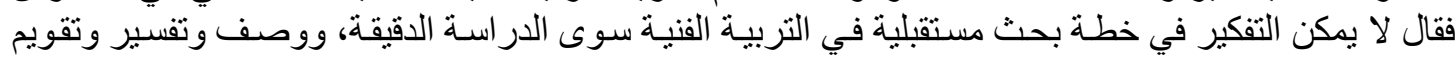

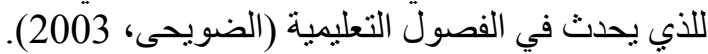

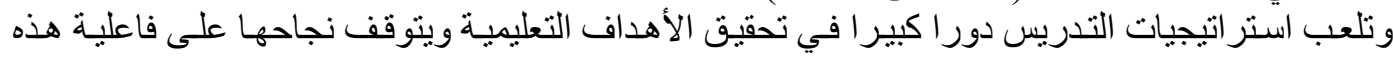
الاستر اتيجيات (الز هر اني، 2008).

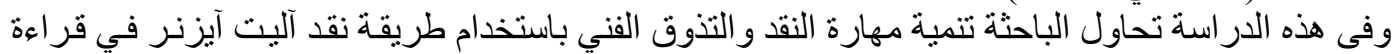
الأعمال الفنية، إضـافة لإكسابهن القدرة على اصدار الأحكام الجمالية، ونقد الأعمال الفنية بأسس موضو عية بعيدة عن النقد الذاتي. مشكيلة البحث: تعتبر طرق التدريس حجر الزاوية في نجاح العمل التدريسي والتعليمي الذي يقوم به المعلم على صعيد

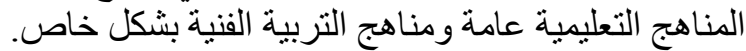
تسعى وزارة التربية والتعليم في بذل الجهود لتطوير وتحديث مناهج التربية الفنية، وركزت على دمج

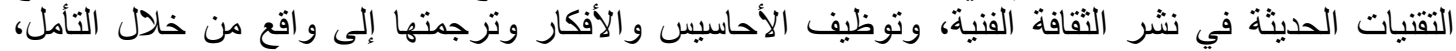
الوصف، التحليل، النقد، و الوعي بالقيمة الجمالية (الطويرقى، ولفئ، 2014).

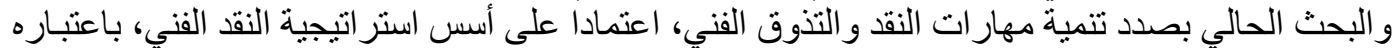

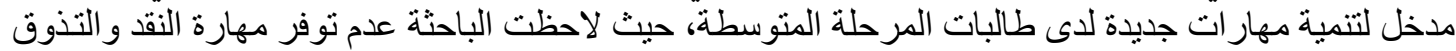

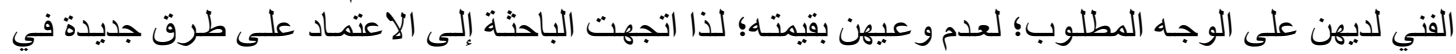

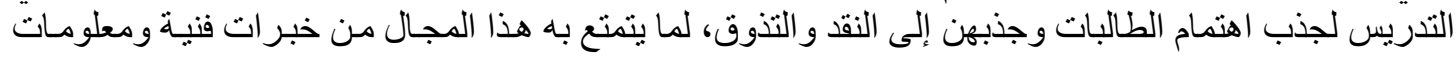

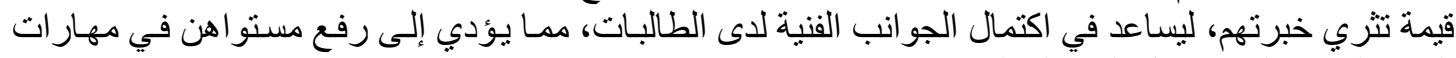

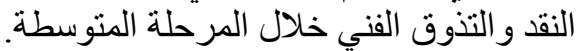

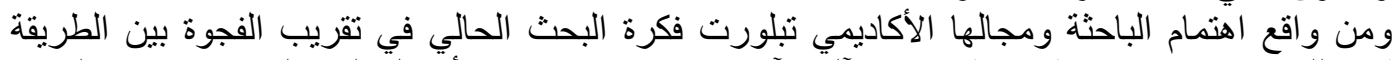

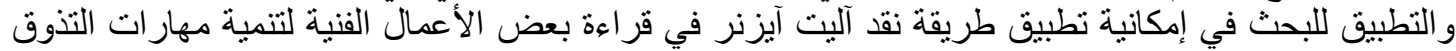




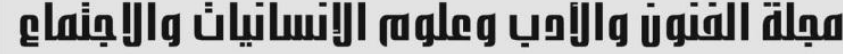

Journal of Arts, Literature, Humanities and Social Sciences www.jalhss.com

Volume (75) January 2022

العدد ( 75) يناير 2022

الفني لطالبات المرحلة المنوسطة، ودعت تلك الفكرة ـ في حدود علم الباحثة ـ عدم وجود در اسة تناولت هذا

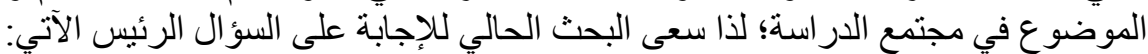

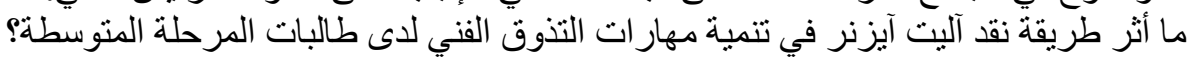
و وتتفرع من السؤال الرئيس الأسئلة الآتية:

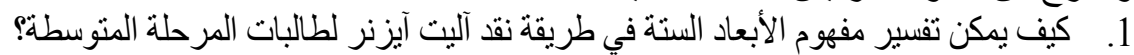
2.

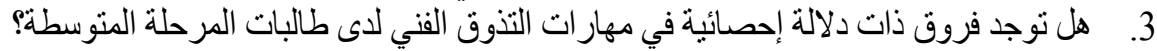

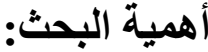
ـ العمل على إثراء البجاء الثبال النقدي للأعمال الفنبة، وتوسيع مدارك المتعلمين نحو فهم العمل الفني، وطبيعة العلاقة بين عناصره لخلق علاقة جمألية. - المساهمة في تطوير تدريس النقد الفني في مقرر التربية الفنية للمرحلة المتوسطة باستخدام طرق النقام النقد الفني.

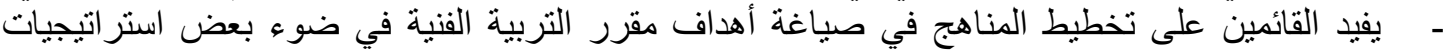
وطرق النقد الفني المختلفة. - مساعدة الطالبات لاكتساب بعض المهار ات النقات النقدية وتنمية التذوق الفني في حل المشكلات و الاحتر ام المتبادل

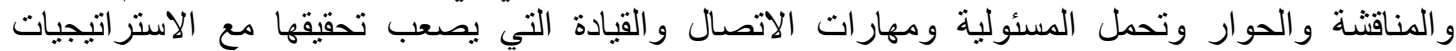

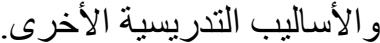

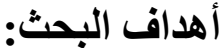

1. تفسير مفهوم البهاء الأبعاد الستة في طريقة نقد آليت آيزنر لطالبات المرحلة المنوسطة.

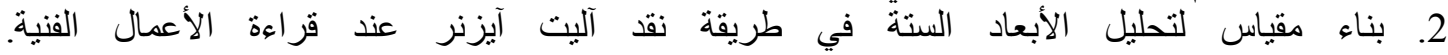

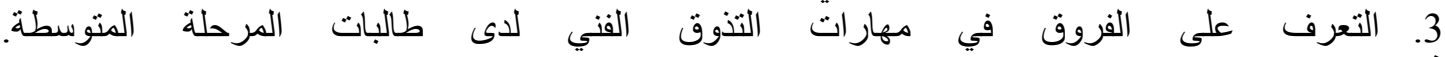

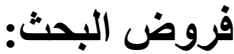
- توجد فروق ذات دات دلالة إحصائية بين متوسط درجات المجمو عتين التجريبية والضابطة في التطبيق البعدي

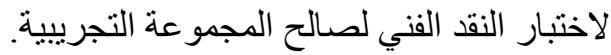

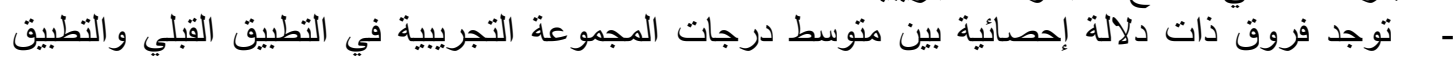
البعدي لاختبار النقد الفني لصالح التطبيق البعدي. حدود موضوعية: تناولت هذه الدراسة آثر طريقة نقد آليت آيزنر في تنمية مهارات التذوق الفني لدى

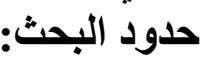
طالبات المرحلة المنوسطة.

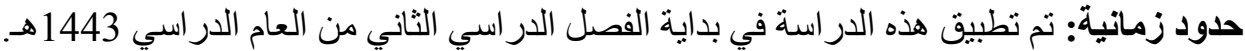

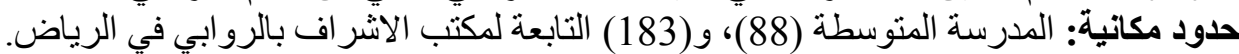

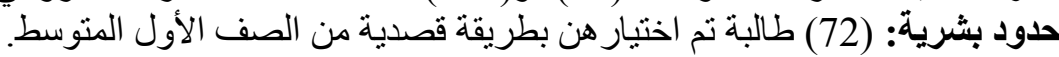

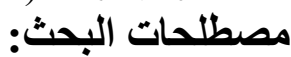
النقل الفني (art criticism):

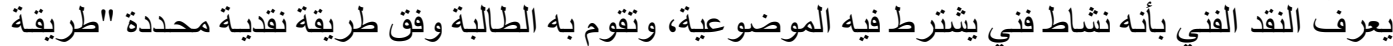

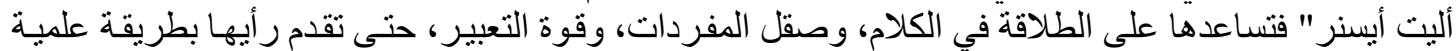

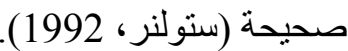
التذوق الفني (art appreciation):

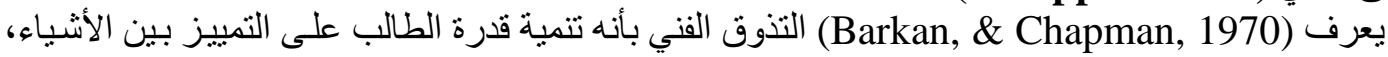

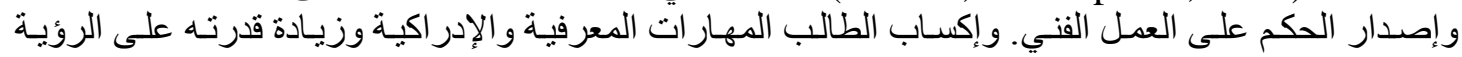

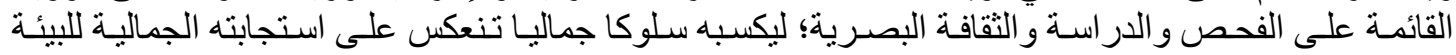

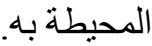
وترى (Rosenthal, 1996) أن التذوق الفني حالة نفسية وجدانيـة، تعتمد على الإدر الك الجمالي للظو اهر الجمالية التي قد ترتبط بالو اقع المجهول الغامض. 


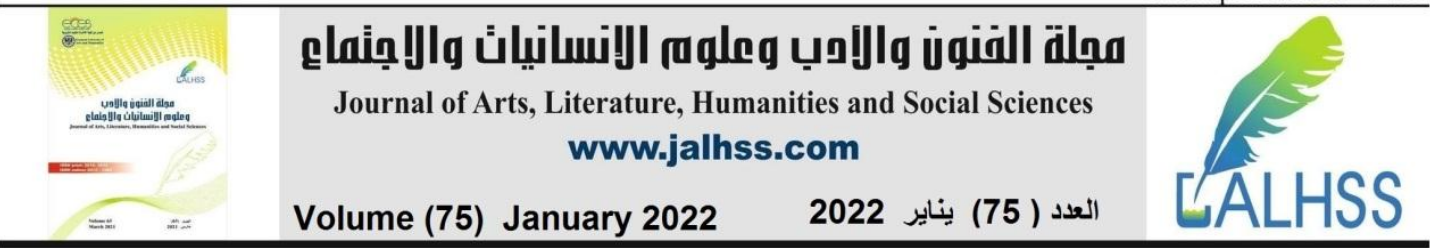

و إجر ائيا يعرف بأنه الدرجـة التي تحصـل عليها الطالبـة في الاختبـار البعدي لمقياس النقد الفني موضوع الدراسة.

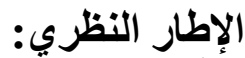

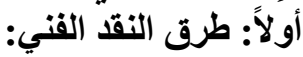

يعرف النقد الفني بأنه قر اءة العمل الفني قر اءة متأنية، وذللك بإخضاع الأعمال الفنية لعمليات أساسية قاعديـة

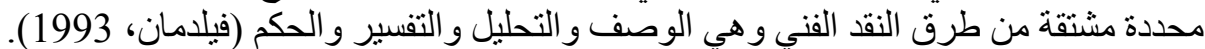
ور غم تنوع التفسير ات لمفهوم النقد الفني، إلا أن غالبيتها تتفق حول مرور التهن مرحلة النقد بتلك المر احل التثلاث

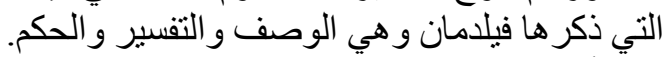

ومن أهم طرق النقد الفني المعاصر ، التي التينتخدمها النقاد في الكتابة عن الأعمال الفنية:

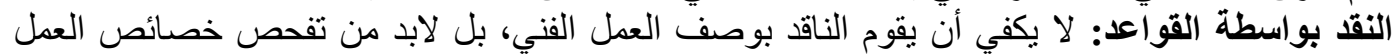

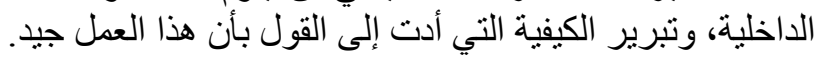

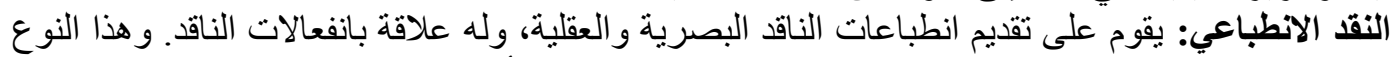

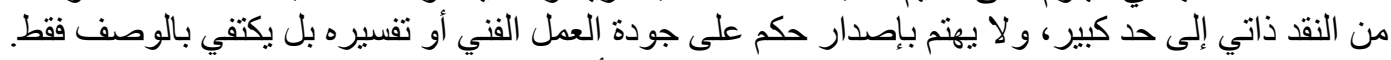
النقد الشكلي: يهتم بموضوع العمل الفني بحيث لا يتأثر الناقد بالانفعالات الثخيّية. ويكتفون بالتحليل الشكلي. النقا السياقي: يهتم بالسياق الذي ظهر فيه العمل الفني، وتشمل جميع المؤثرات الاجتماعية والاقتصادية

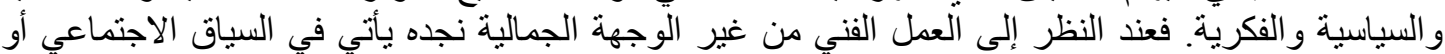

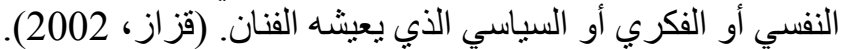

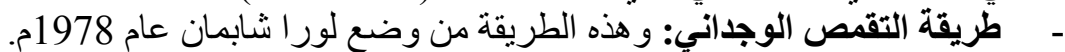

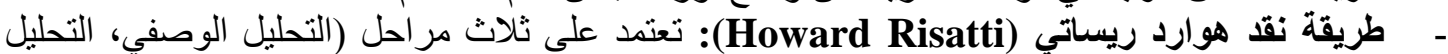

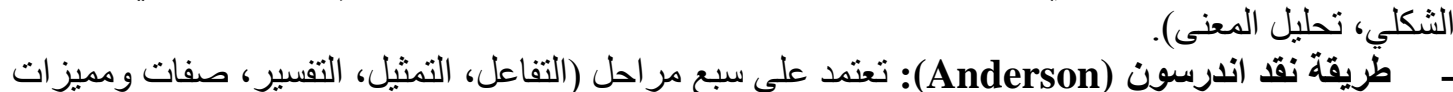

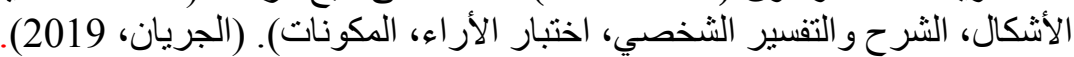
- طريقة نقد آليت آيزنر (Elliot Eisner): وهي طريقة النقد التي استخدمتها الباحثة في هذه الدراسة.

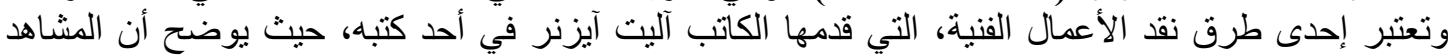
عندما يتعرض للعمل الفني يمكن أن ينظر إليه من الأبعاد التالية:

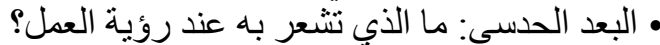

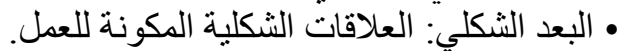
• البعد الرمزي: الرموز التيدي يحويها العمل ومعانيها وقيمتها في العمل.

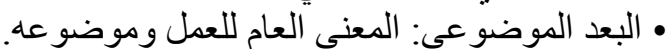

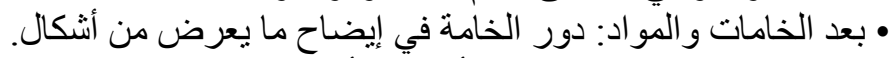

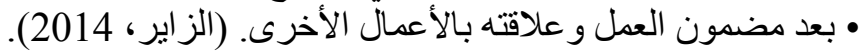

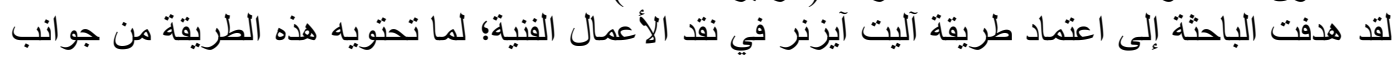

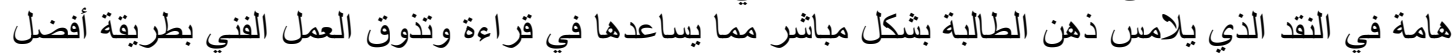

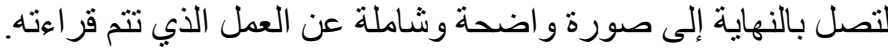

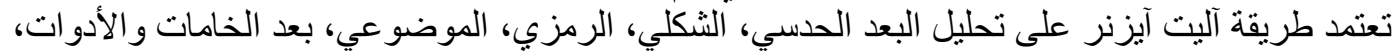

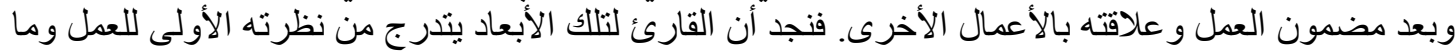

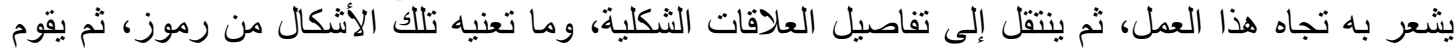
بتحليل معانيها ومدى قيمتها في العمل نفسه، وبالنهاية يكون صورة واضحة فودة عن المعنى العام للعمل، فيستطيع

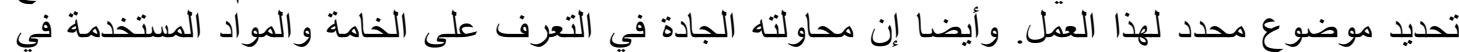

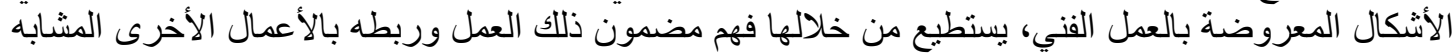
لله في أي من الأبعاد السابقة. 


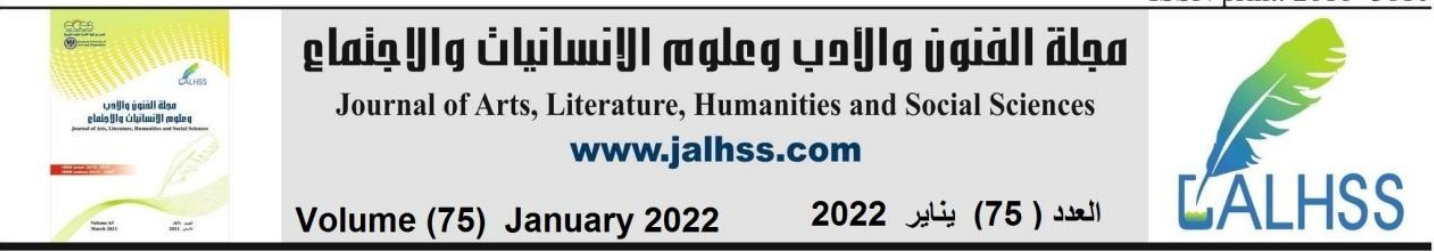

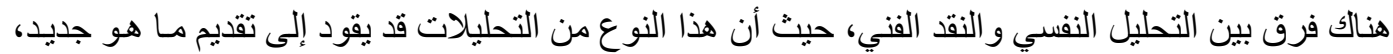

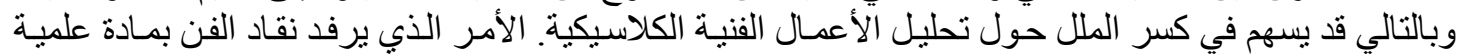
جديدة ومثنيرة في نفس الوقت فئ. (المعمري، 2013).

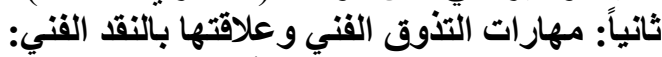

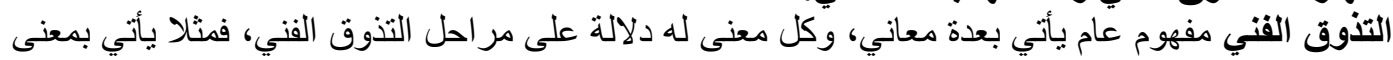

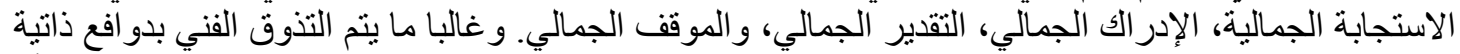

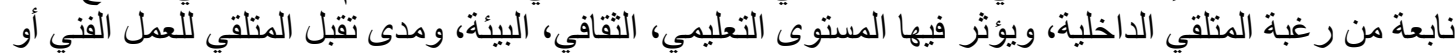
رفضاه له.

أما النقل الفني فهو المرحلة التي تلي مراحل التذوق، ولكنه مرحلة من مراحله المتقدمة، ويسمى الحكم الجمالي؛ لأن المتلقي في هذه المرحلة يمكنه إصدار الحكم على العمل الفني، ويكون مؤهلا لهال لهذه المرحلة الفئ عندما

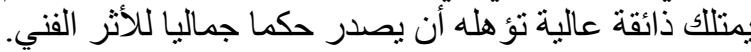

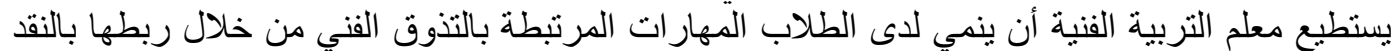

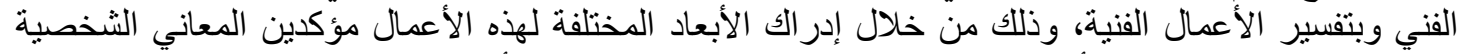

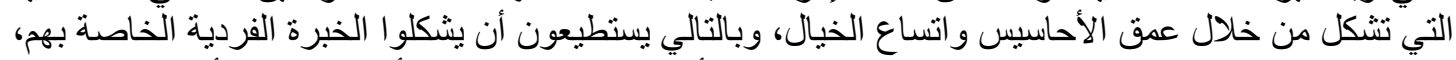

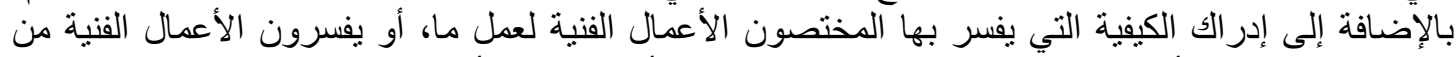

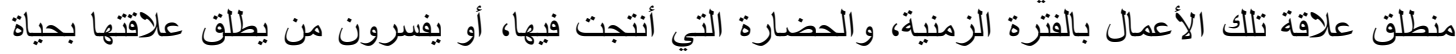

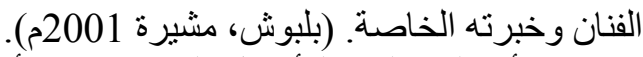

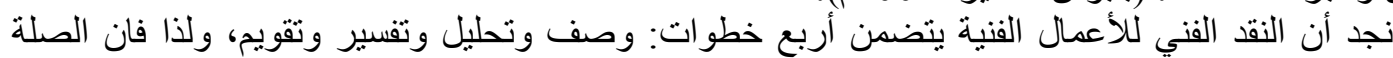

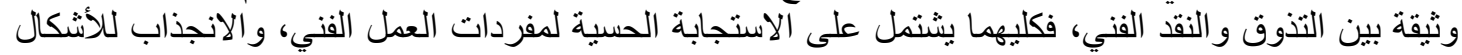

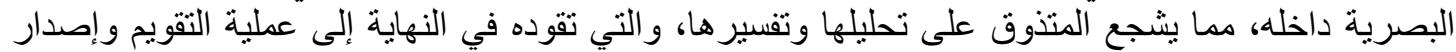

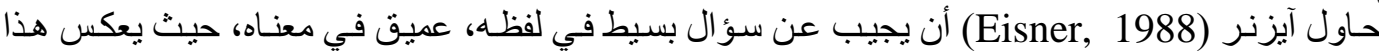
الحكم عليه.

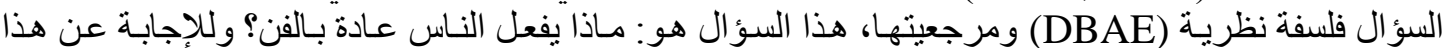

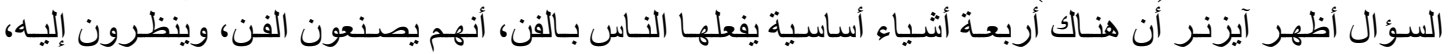

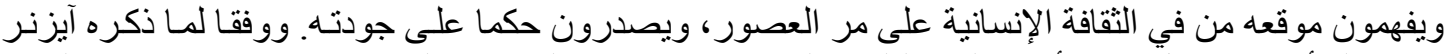

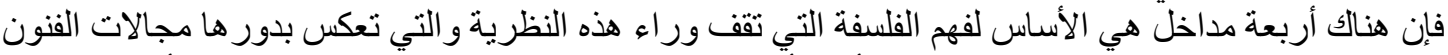

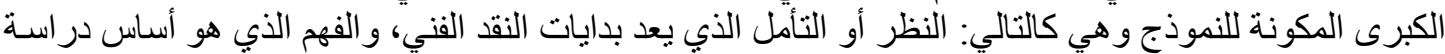

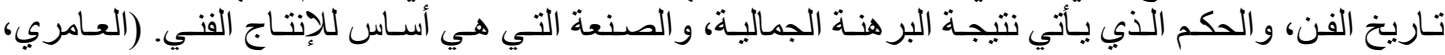
. (2014

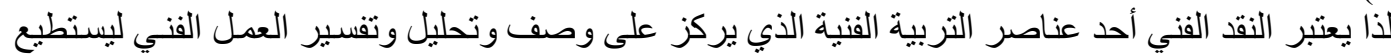

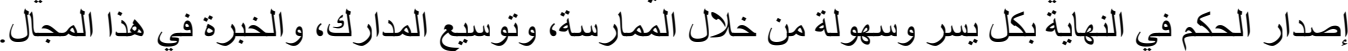

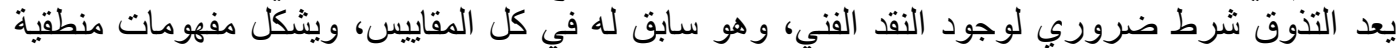

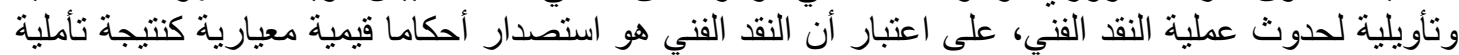

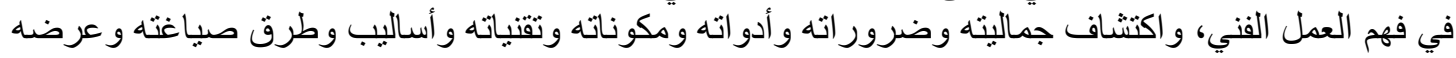

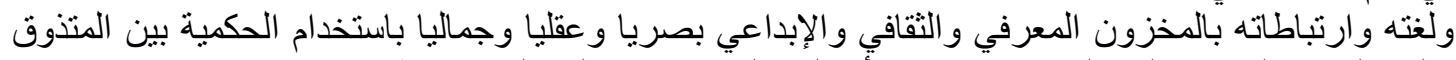

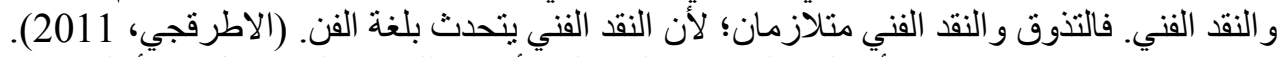

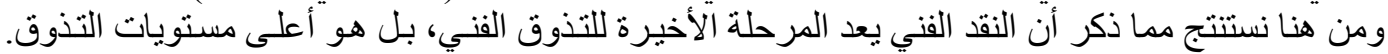

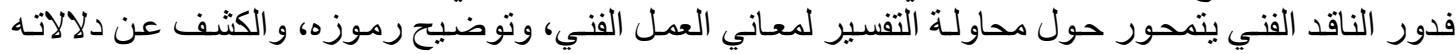




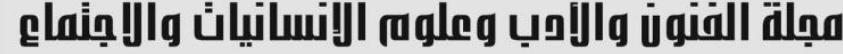

Journal of Arts, Literature, Humanities and Social Sciences www.jalhss.com

Volume (75) January 2022

العدد ( 75) يناير 2022

- - - التخطيط لإثر اء المدركات البصرية والمعرفية و الفنية التي تساهم في النمو الإبداعي.

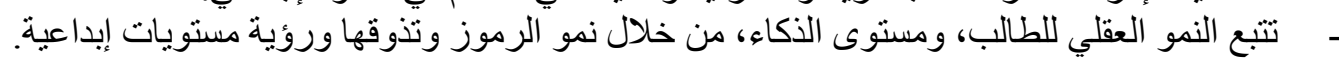

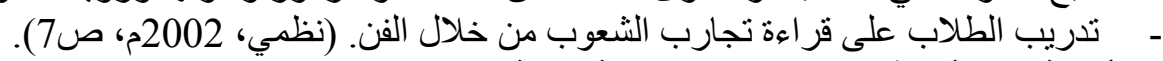
ب. أهمية دراسة التذوق الفني لمعلم التربية الفنية:

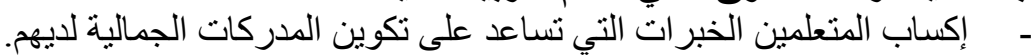

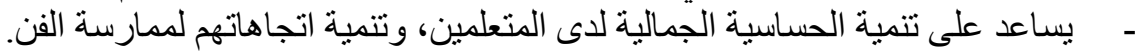

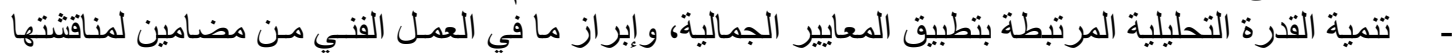

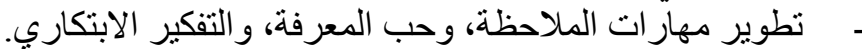
بشكل موضو عي. ـ ـ ـ يساعد المتذوقين على تنظيم أفكار هم للوصول إلى قرارات منطقية للحكم على الأعمال الفنية. (دياب،

• دور معلم التربية الفنية في تنمية التذوق الفني:

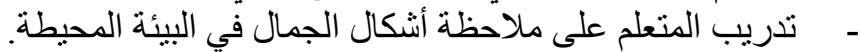

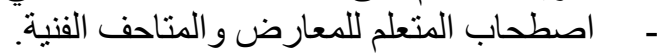

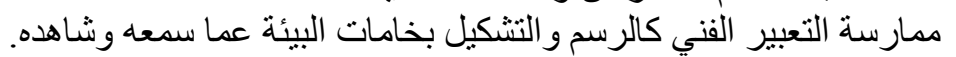

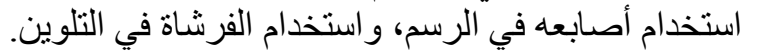

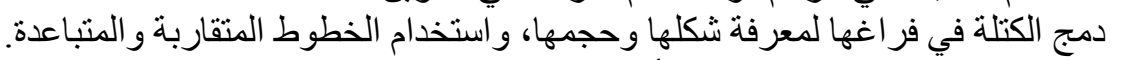

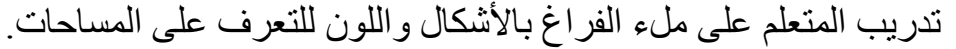
فلك الأشياء وتركيبها، لمعرفة العلاقة بين الكتل و الأجزاء العاء (البنا، 1992).

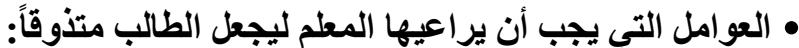

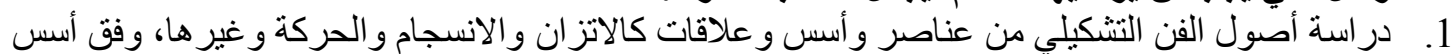

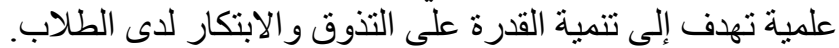

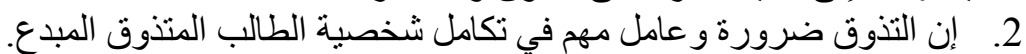

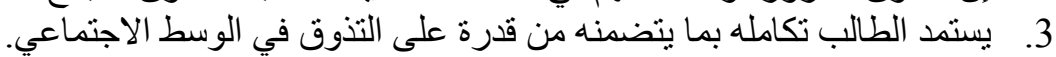

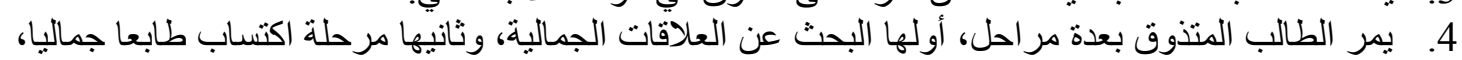

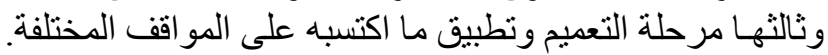
5. إن الممارسة العملية للفن تساعد الطالب على على انتقال القيم التي تعلمها إلى مو اقف الحياة. (https://www.minia.edu.eg/kind/files/abda3fan).

• مهارات النقد والتذوق الفني لطالب المرحلة المتوسطة: 1. مهارات النقا والتذوق الفني:

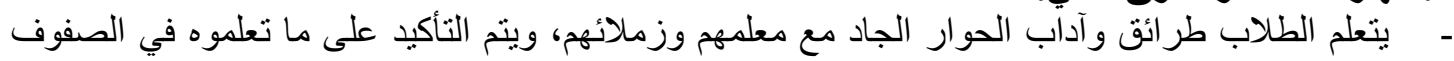
العليا من المرحلة الابتدائية.

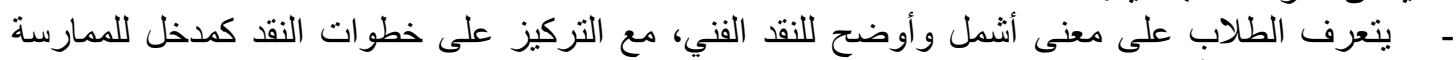

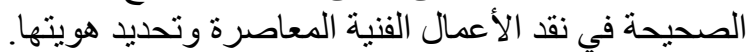

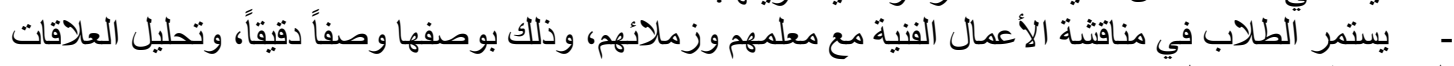
التي تربط بينها في التكوين. - مالاستمر ار في استعر اض اضل الأعمال الفنية من الفنون و الثقافات المختلفة.

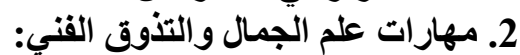

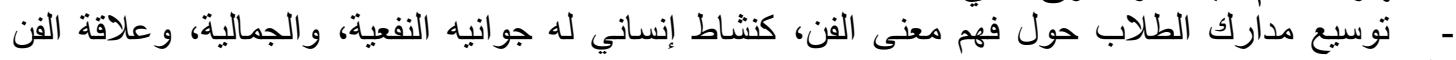
بالحضارة. - يستمر الطلاب في تعلم بعض المصطلحات، التي تقودهم إلى تحسين لغتهم الفنية.

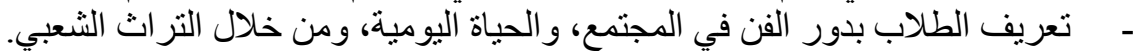

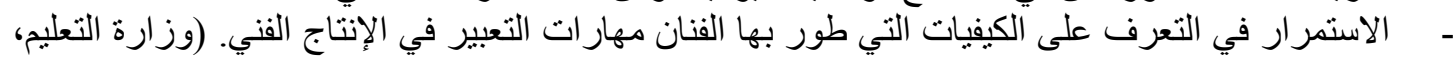




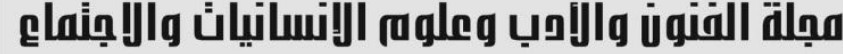

Journal of Arts, Literature, Humanities and Social Sciences www.jalhss.com

Volume (75) January 2022

العدد ( 2022 يناير

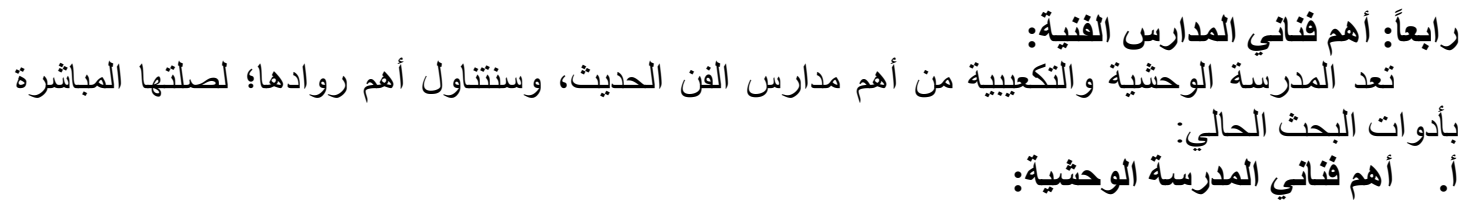
القنان هنري ماتيس 1954-1869) Henri Matiss م):

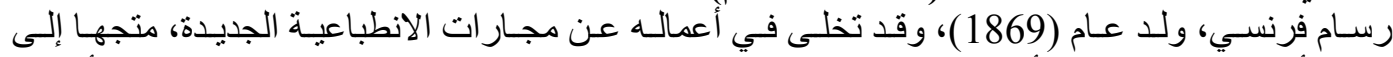
الوحشية، و أضـاف في رسوماته أسلوب جديد، فظهر الطـابع الزخرفي الذي تميز بالحريـة في إيقاعـات الألوان، و والخطوط. ويمكن أن نلاحظ تأثر ماتيس في رسم وجوه شخصياته النسائية برسوم المخطوطات العربية. (هيكل، 2004م).

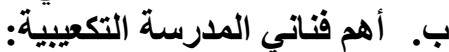

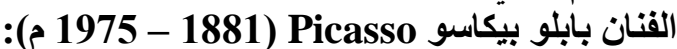
فنان أسباني ولا عام (1881)، ظهرت لدان لديه مهارة فن الرسم منذ صغره ه، حيث تعلم من و الده الذي كان بعمل

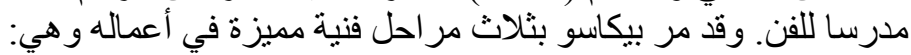

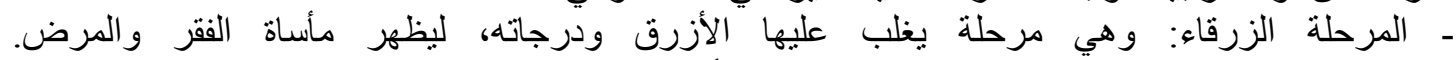

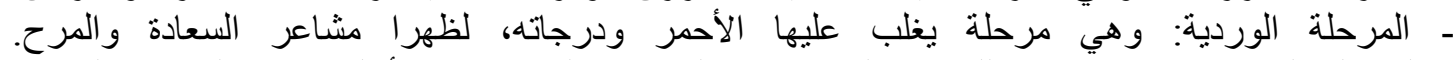
ـ المرحلة التكعيبية: وكانت بداية للمذهب التكعيبي، اختلف فيها الموضوع والتية والأسلوب عن المذاهب السابقة،

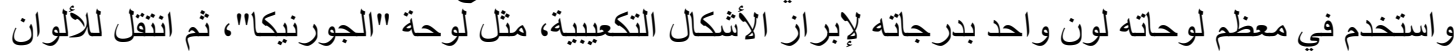

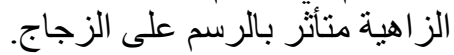

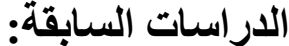

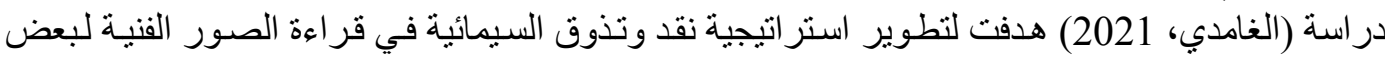

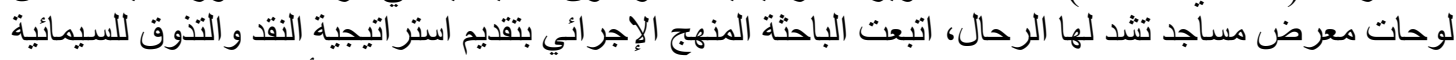

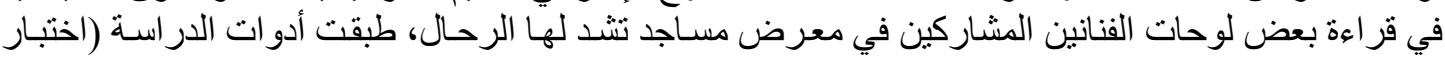

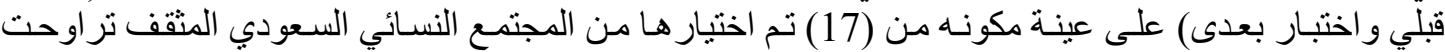

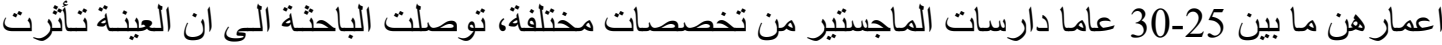

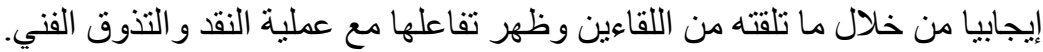
در اسة (الدوسري؛ والثهري، 2018) هدفت إلى التحقق من حقيقة تفعيل النقد الفني في المدارس المتوسطة، التها،

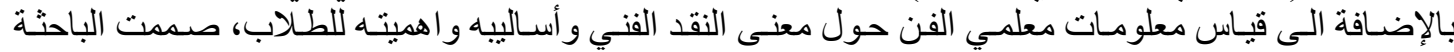

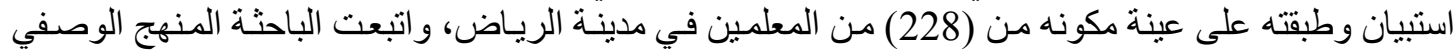

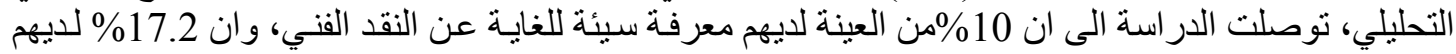

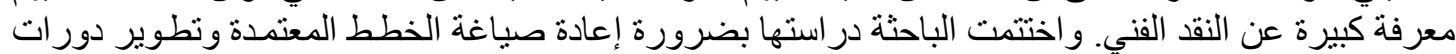
تتعلق بالنقد الفني للمعلمين من اجل ونل زيادة معرفتهم.

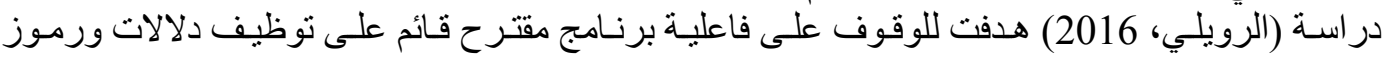

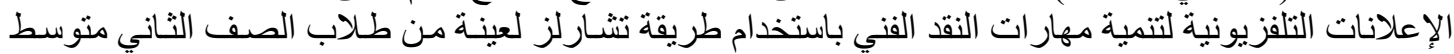

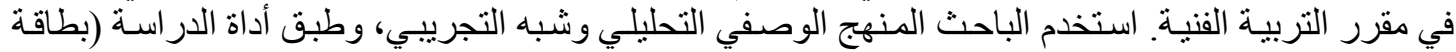

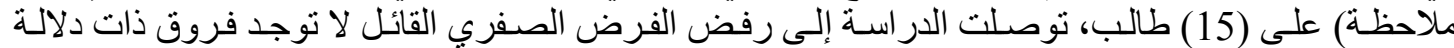

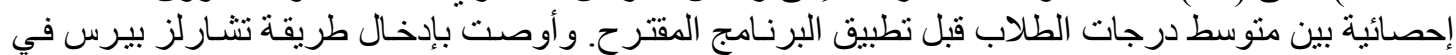
تتمية مهار ات النقد الفني في مقرر التربية الفئة الفنية.

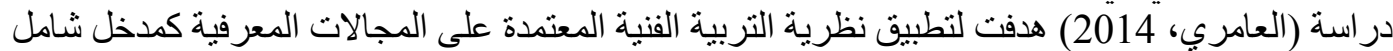

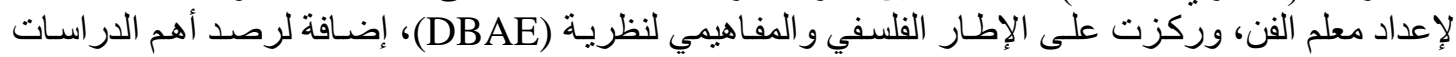

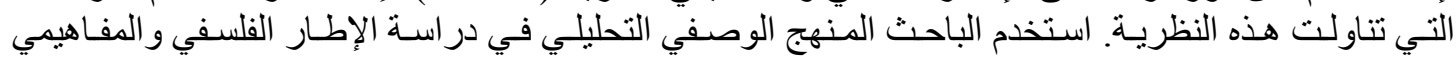

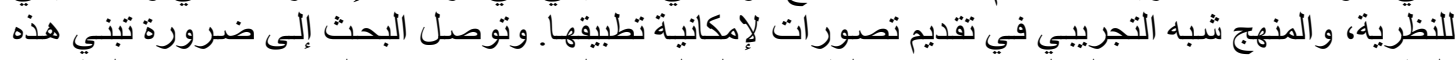

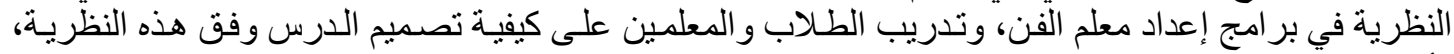
و أوصى الباحث بتجريب الوحدات المقترحة في الحقل التربوي. 


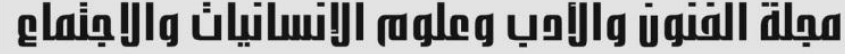 \\ Journal of Arts, Literature, Humanities and Social Sciences www.jalhss.com}

Volume (75) January 2022

العدد ( 2022 يناير

در اسة (Duh, Korosec, 2014) هدفت إلى تنميـة قدر ات التذوف الفني لدى طلاب المدارس الابتدائية،

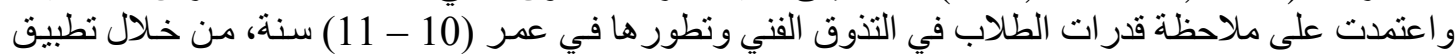

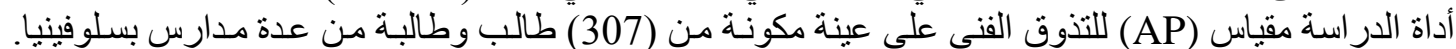

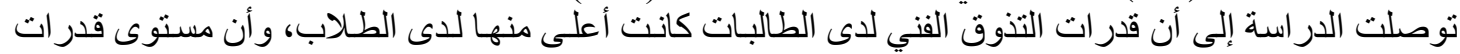

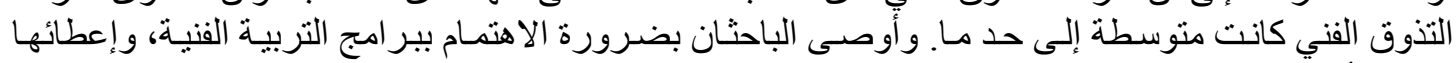

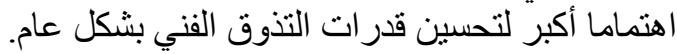
التعقيب على الاراسات السابقة:

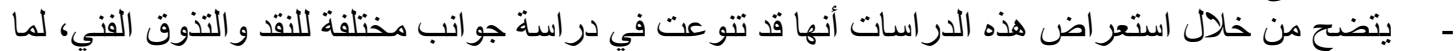

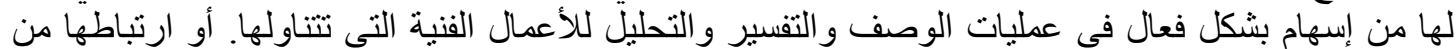
حيث أن النقد الفني يمثل أحد مجالات في نظرية التربية التربية الفنية.

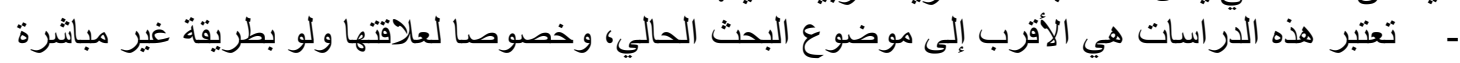

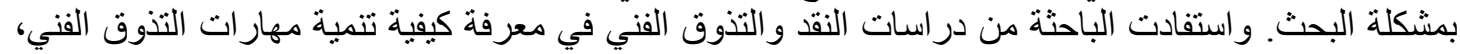

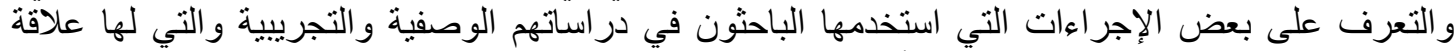

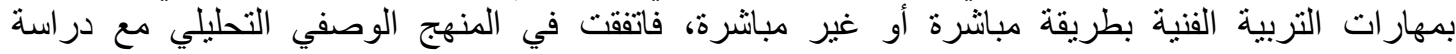
(الدوسري؛ والثهري، 2018)، (العامري، 2014)، والمنهج شبه التجريبي مع دراسة (الرويلي، 2016).

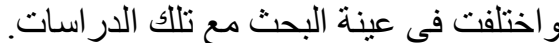

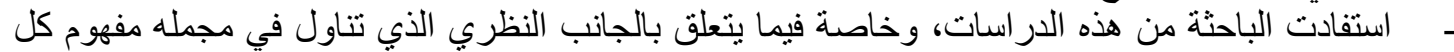

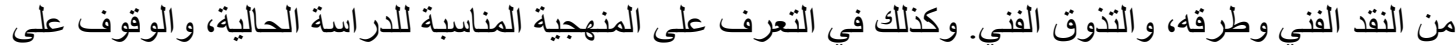

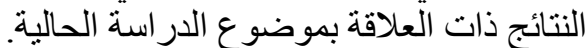

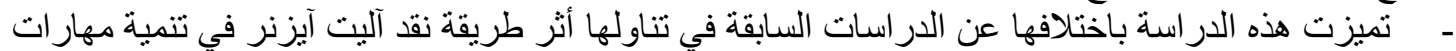

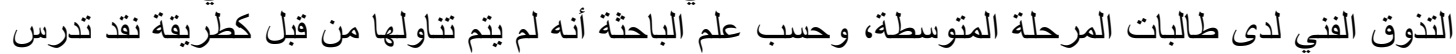

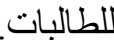

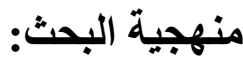

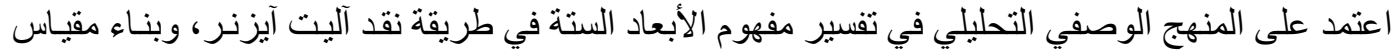

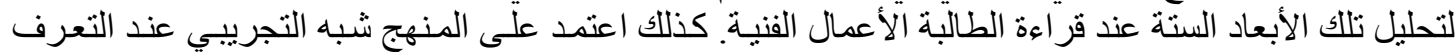
على الفروق في مهار ات التذوق الفني بين المجمو عتين.

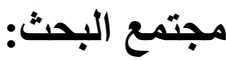
طالبات مدارس الرياض الحكومية التابعة لمكتب الإشر اف التربوي بالروابي.

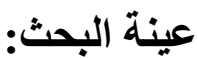

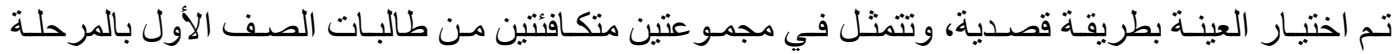

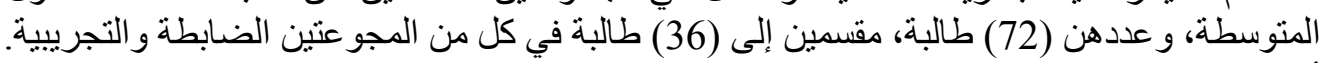
أدواث الإحث: - اختبار قبلي واختبار بعدي، بطلب من الطالبة تحليل العمل الفني الموجود أمامها بطريقة نقد آليت آيزنر ـوقد

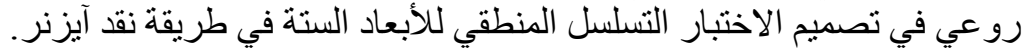

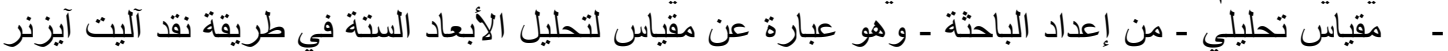

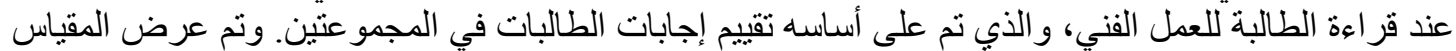

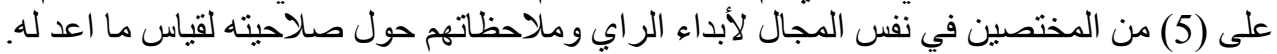

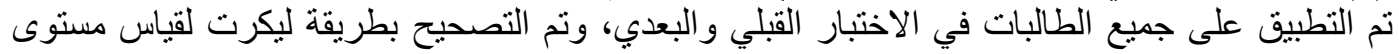

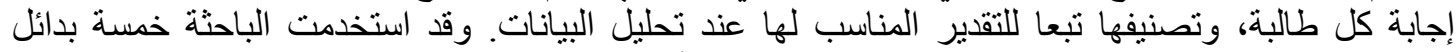
لتصحيح الإجابات على الاختبار ، وذلك بإعطاء كل عبارة الأوزان النسبية التالية: 


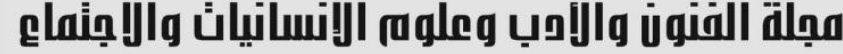

Journal of Arts, Literature, Humanities and Social Sciences www.jalhss.com

Volume (75) January 2022

العدد ( 2022 العناير

جدول (1): أوزان كل عبارة في الاستبيان أثناء تصحيح الإجابات

\begin{tabular}{|c|c|c|c|c|c|}
\hline ضعيف & منمكنة إلى حد & جيد & جيد جدا & ممتاز & العبارة \\
\hline 1 & 2 & 3 & 4 & 5 & الدرجـــــة \\
\hline
\end{tabular}

\section{تطبيق طريقة نقد آليت آيزنر:} المقابلة الأولى: تطبيق الاختبار القبلي على المجموعتين؛ لتحديد مهار اتلئ التذوق الفني قبل توضيح طريقة نقد آليت آيزنر. ثم اختيار المجموعة التجريبية فقط، واستعراض الهم أهم المدارس في الفن الحديث، ومن بينها المدرسة الوحشية والتكعيبية.

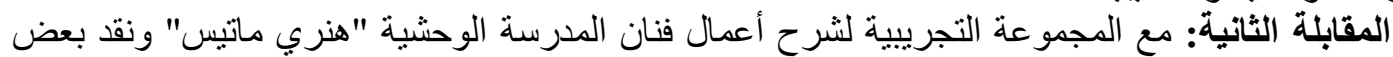

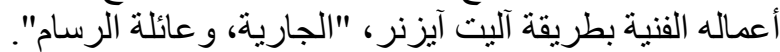

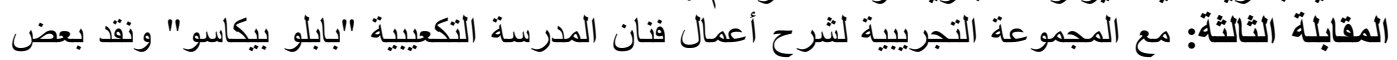

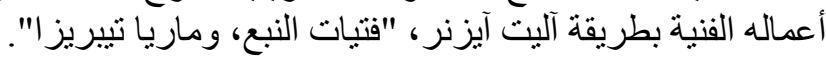

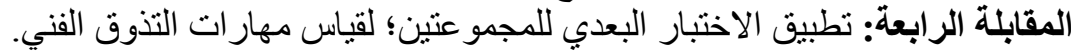

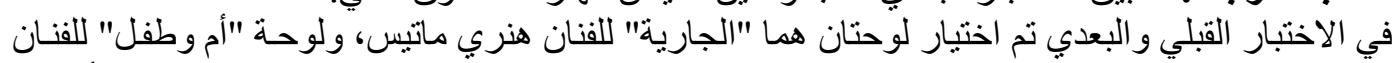

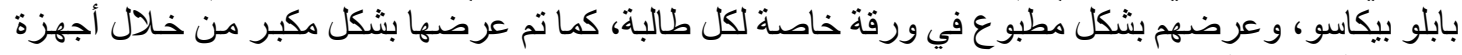

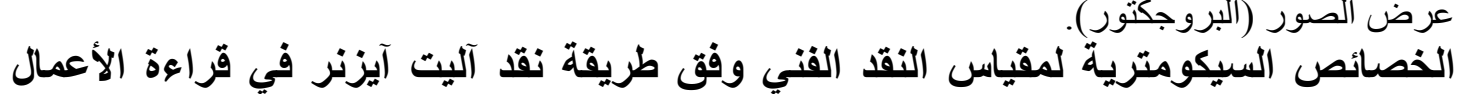
استخرجت دلالات الصدق لمقياس النقد الفني وفق طريقة آليت آيزنر والتي تكونت من (6) أبعاد للنقد

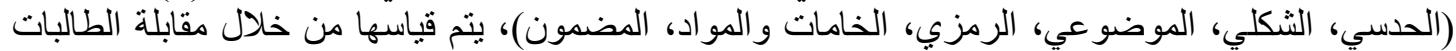

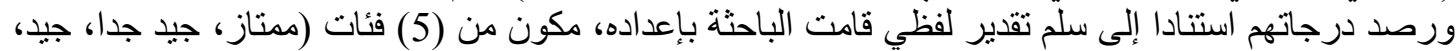

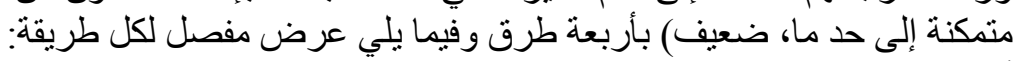

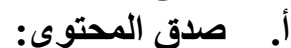

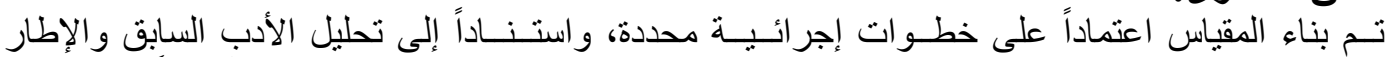

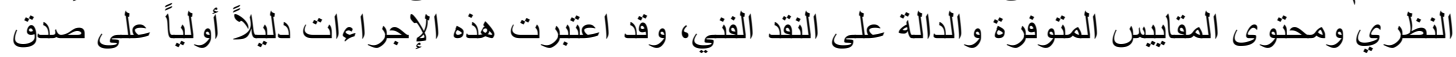

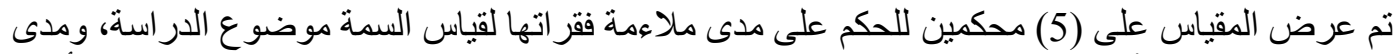

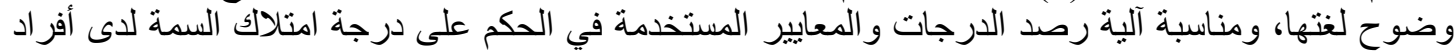

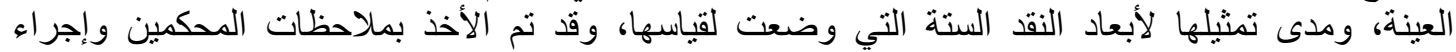

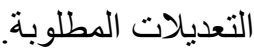

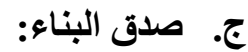

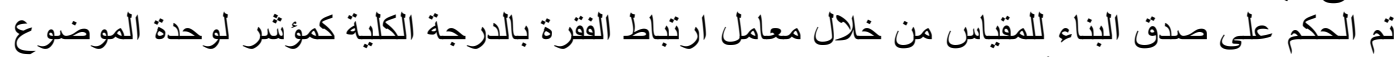

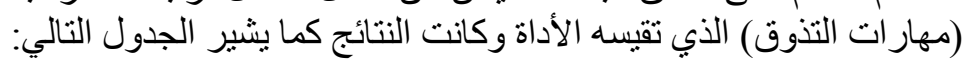

جدول (2): قيم معاملات الارتباط بين أبعاد النقد الفني والدرجة الكلية للمقياس

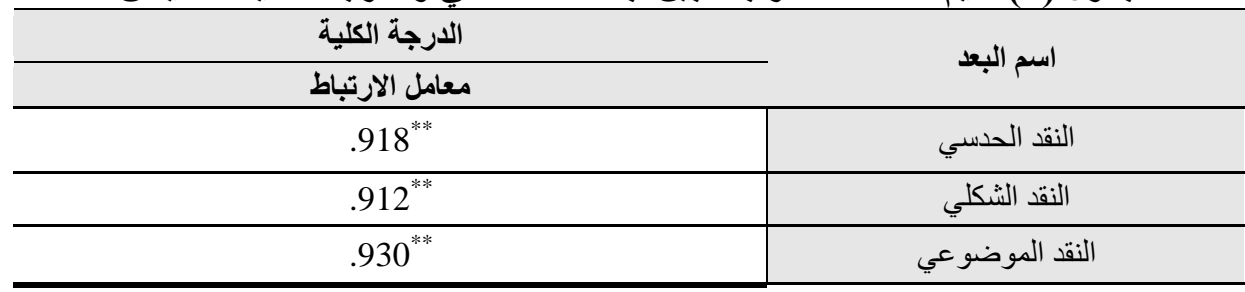




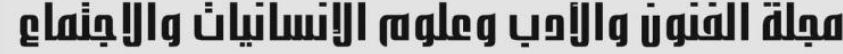

Journal of Arts, Literature, Humanities and Social Sciences www.jalhss.com

العدد ( 2022 العاير

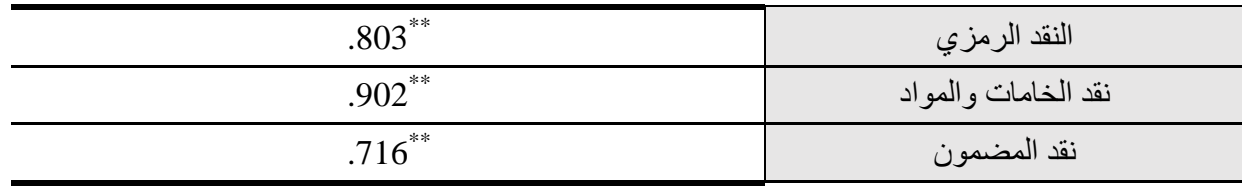

Correlation is significant at the 0.01 level (2-tailed).

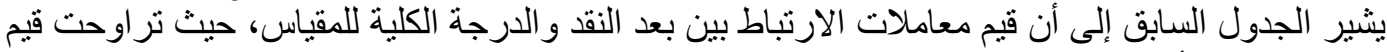

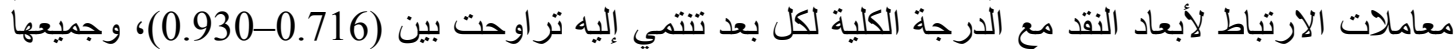

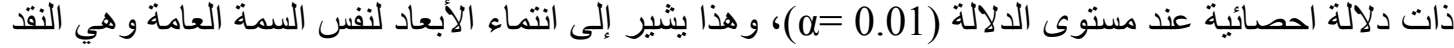

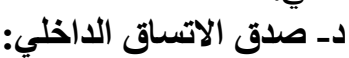

نم التحقق من صدق الاتئ لاتساق الداخلي من خلال ايجاد منوسط الفقرات وقيمة معامل الارتباط وقيمة ألفا في

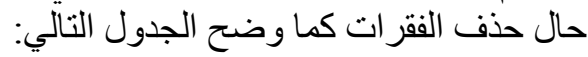

\begin{tabular}{|c|c|c|c|c|}
\hline معامل ألفا في حال & معال حذف الارتباط في & التباين في حال & في حال حذف الفقرة & اسم البعد \\
\hline 0.807 & 0.509 & 83.127 & 37.17 & النقد الحدسي \\
\hline 0.760 & 0.893 & 71.181 & 35.79 & النقد الشكلي \\
\hline 0.764 & 0.886 & 72.139 & 34.88 & النقد الموضوعي \\
\hline 0.776 & 0.913 & 75.577 & 35.83 & النقد الرمزي \\
\hline 0.777 & 0.759 & 74.901 & 35.00 & نقد الخامات و المو اد \\
\hline 0.787 & 0.881 & 78.463 & 35.71 & نقد المضمون \\
\hline
\end{tabular}

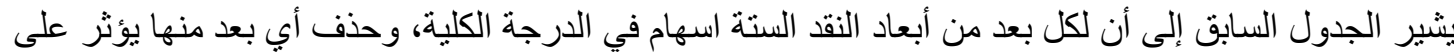
قيم المتوسط الحسابي و الانحر اف المعياري ومعاملات الارتباط مما يؤكد على أهمية جميع أبعاد النقد في قياس

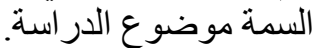

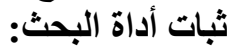
تم التحقق من ثبات الأداة من خلال ثبات الإعادة، إذ تم تصحيح استجابات أفر اد العينة من قبل محكمين اثنين

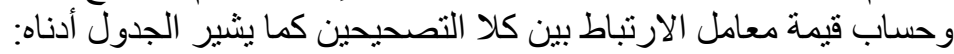

جدول (4): معاملات الثبات بطريقة الإعادة لأداة البحث

\begin{tabular}{|c|c|c|}
\hline ثبات الإعادة & البعد & المقياس \\
\hline 0.89 & النقا الحدسي & \multirow{7}{*}{ 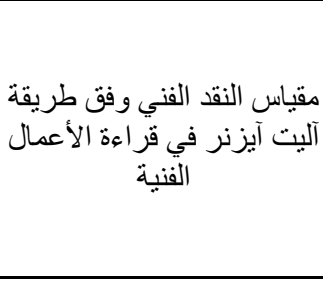 } \\
\hline 0.91 & النقد الشكلي & \\
\hline 0.90 & النقد الموضوعي & \\
\hline 0.87 & النقد الرمزي & \\
\hline 0.85 & نقد الخامات و المو اد & \\
\hline 0.82 & نقد المضمون & \\
\hline 0.86 & الدرجة الكلية & \\
\hline
\end{tabular}

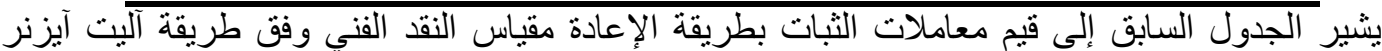

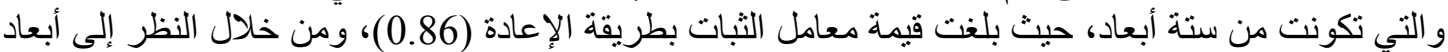

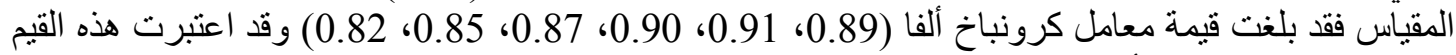

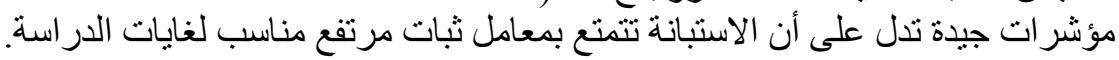




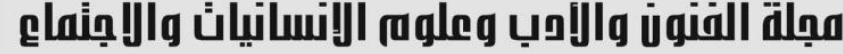

Journal of Arts, Literature, Humanities and Social Sciences www.jalhss.com

السؤال الأول: كيف يمكن تفسير مفهوم الأبعاد الستة في طريقة نقد آليت آيزنر لطالبات المرحلة المتوسطة؟

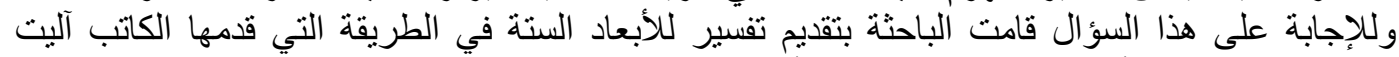

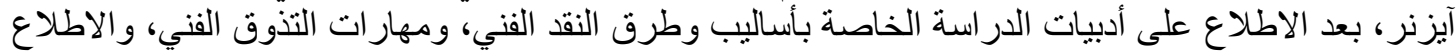

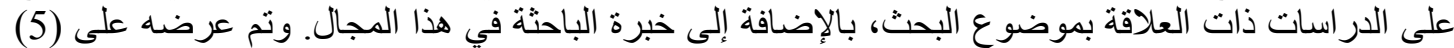

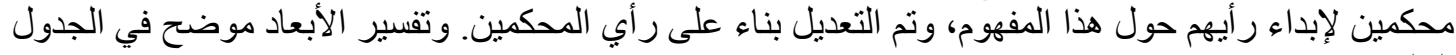

جدول (5) تفسير الأبعاد الستة لطريقة نقد أليت أيزنر في قراءة الأعمال الفنية (من إعداد الباحثة)

\begin{tabular}{|c|c|c|}
\hline تفسـير الباحثة لأبعــاد آليت آيزنر & أبعــاد آليت آيزنر & b \\
\hline 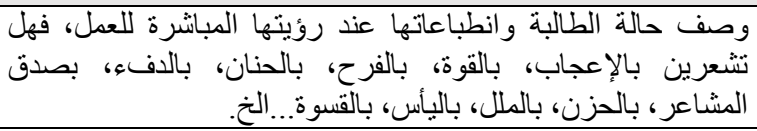 & 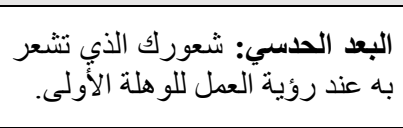 & 1 \\
\hline 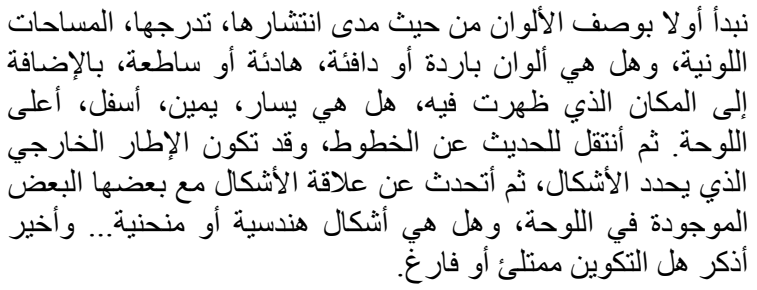 & البكونة اللعكلي: العلاقات الشكلية & 2 \\
\hline بالنسبة للمشتشاهد (أي ماذا تعني للمشناهد)؟ منشابهة أو مختلفة؟ وما هي دلالاتها & البعل الرمزي: الرمانيها وقيمتها في العمل. يحويها & 3 \\
\hline 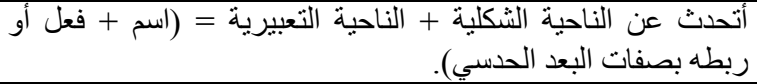 & اللعمل و الموضوضوعي: المعنى العام & 4 \\
\hline 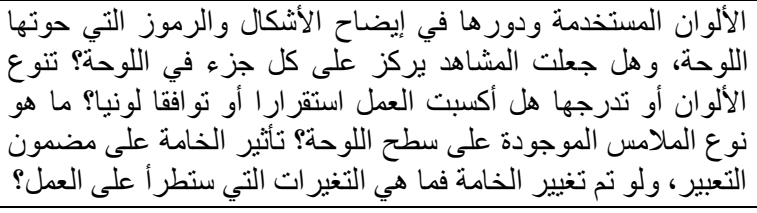 & في إيضاح الخامات والمعرضاد: دور الثكال. & 5 \\
\hline رالمضطون، مع بأعمال أخرى نتشابه مع هذا العمل من حيث الثكل أو & 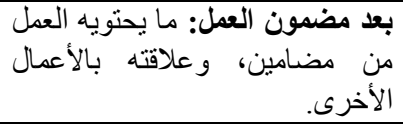 & 6 \\
\hline
\end{tabular}

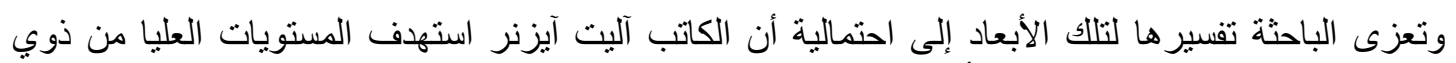

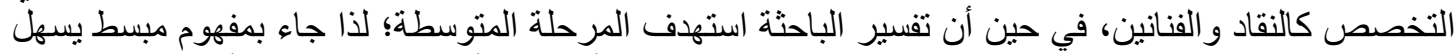

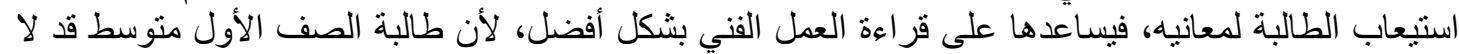

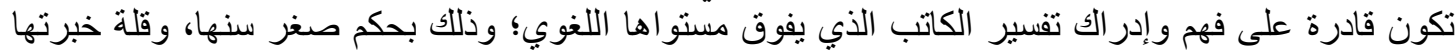

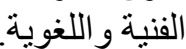
السؤال الثاني: ما مدى مناسبة بناء مقياس لتحليل الأبعاد الستة في طريقة نقد آليت آيزنر عند قراءة الأعمال الفنية: (الفوال وللإجابة عن هذا السؤال قامت الباحثة بيناء مقياس يمكن من خلاله تقييم إجابات الطالبات في الاختبار القبلي

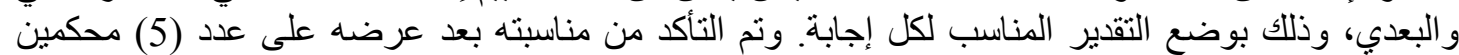

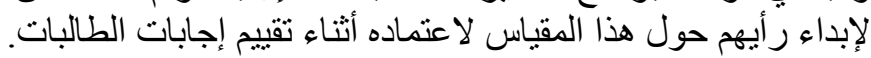




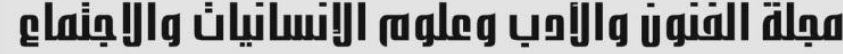

Journal of Arts, Literature, Humanities and Social Sciences www.jalhss.com

Volume (75) January 2022

العدد ( 2022 يناير

جدول (6) مقياس لتحليل الأبعاد الستة في طريقة نقد آليت آيزنر عند قراعة الأعمال الفنية في الاختبار القبلي والبعدي، ووضع التقدير المناسب لكل إجابة (من إعداد الباحثة)

\begin{tabular}{|c|c|c|c|}
\hline الإجابة المناسبة للتقدير & التقدير & البعــــ & r \\
\hline 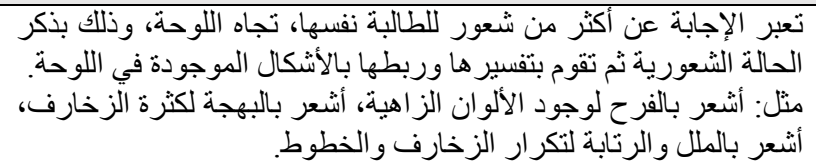 & 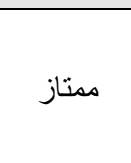 & \multirow{5}{*}{ 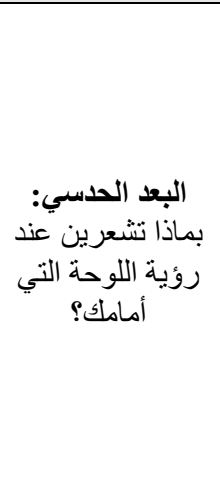 } & \multirow{5}{*}{1} \\
\hline تكتب الطالبة إجابة صحيحة، ولكن الإجابة لشعور و واحد فقط. & جيد جدا & & \\
\hline 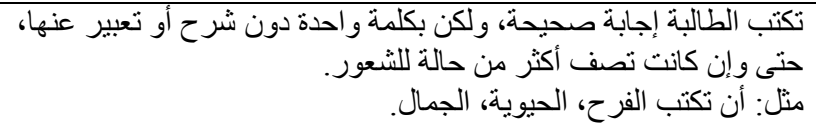 & جيد & & \\
\hline 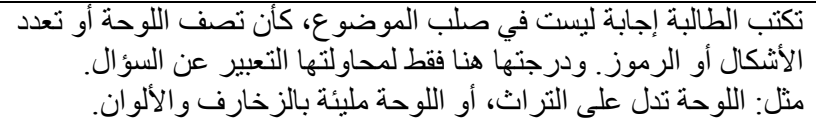 & 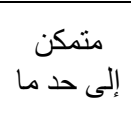 & & \\
\hline لا توجد إجابة، أو الإجابة خاطئة ليست في صلب الموضوع. & ضعيف & & \\
\hline 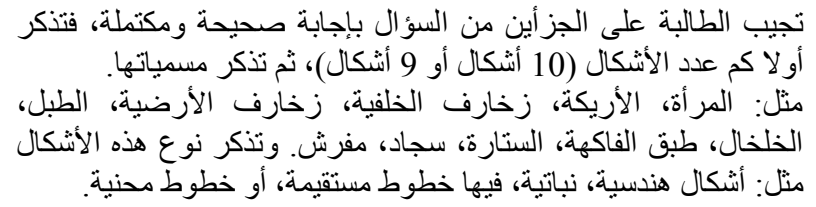 & متاز & \multirow{5}{*}{ عدد الأشكال التّي: } & \multirow{5}{*}{2} \\
\hline 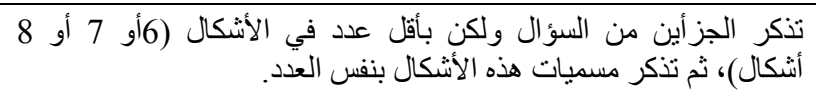 & جيد جدا & & \\
\hline 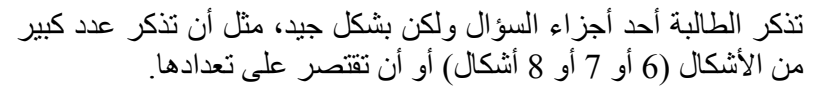 & جيد & & \\
\hline تذكر الطالبة أحد أجزاء السؤال، وتختصر عدد الأشكال وبشكل أقل من 5 أنثال & 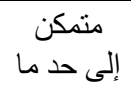 & & \\
\hline لا توجد إجابة، أو الإجابة خاطئة ليست في صلب الموضوع. & ضعيف & & \\
\hline تحاول الطالبة إبداء أكثر من موضوع للوحة، وبطريقة مختلفة في التعبير. & 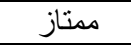 & \multirow{5}{*}{ البعد الموضوعي: } & \multirow{5}{*}{3} \\
\hline وقامكت بتفسيره. مالبة من الإجابة بشكل صحيح وذكرت موضوع و واحد للوحة & جيد جدا & & \\
\hline 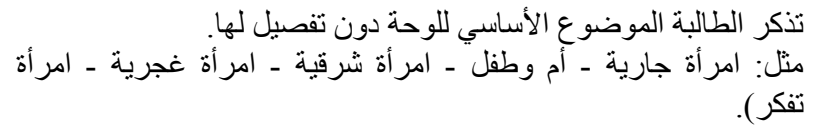 & جيد & & \\
\hline 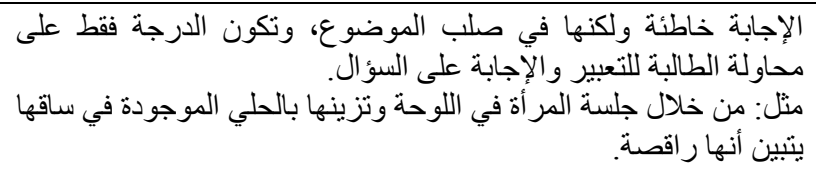 & 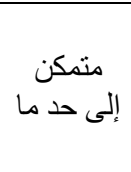 & & \\
\hline لا توجد إجابة، أو الإجابة خاطئة ليست في صلب الموضوع. & ضعيف & & \\
\hline 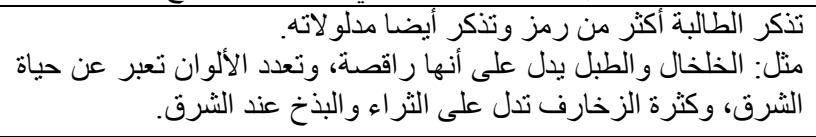 & ممتاز & \multirow{5}{*}{ ما هي الرموز الرمزي: التئي } & \multirow{5}{*}{4} \\
\hline تربط الطالبة بين الرمز ودلالته، ولكن تقتصر على رمز واحد. & جيد جدا & & \\
\hline تعدد رموز اللوحة، دون ذبل، زلو دلالتها. & جيد & & \\
\hline تذلكر رلخال، زخارف، من رمبل، ألوحان، زوخارف ذكر دلالته. & إلى حدمن ما & & \\
\hline لا توجد إجابة، أو الإجابة خاطئة ليست في صلب الموضوع. & ضعيف & & \\
\hline
\end{tabular}




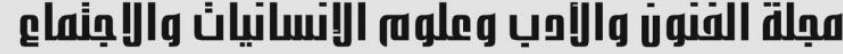

Journal of Arts, Literature, Humanities and Social Sciences www.jalhss.com

Volume (75) January 2022

العدد (75) يناير 2022

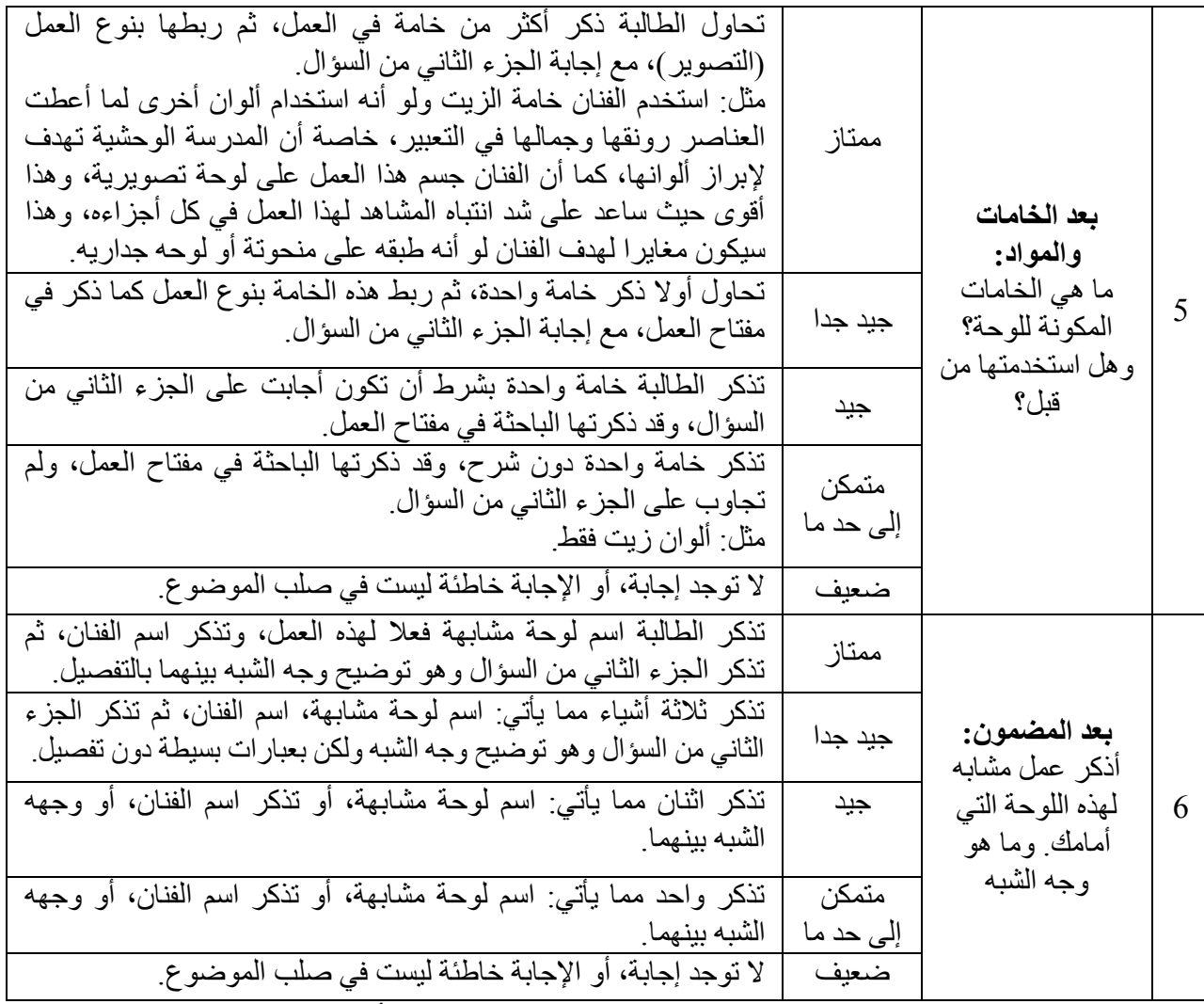

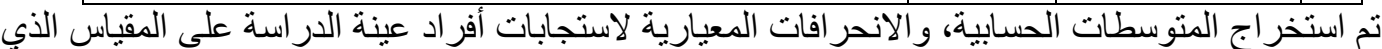

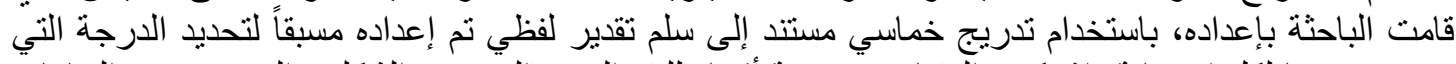

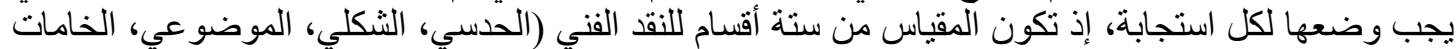

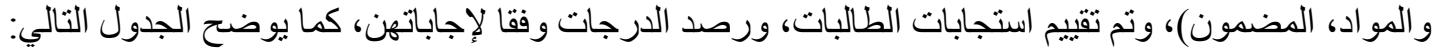

جدول (7): المتوسطات الحسابية والانحرافات المعيارية لاستجابات أفراد عينة الدراسة على المقياس وفق طريقة آيزنر لإستج

\begin{tabular}{|c|c|c|c|c|c|c|}
\hline الاستخذام & الجانبة & الالحعراف & الحسابي & ن نص الفقزة & تمثلاه الفقرة الذي & رالفقرة \\
\hline متوسطة & 5 & 1.01 & 2.57 & ما الذي تثتعر به عند رؤية العمل؟ & الحدسي & 1 \\
\hline متوسطة & 1 & 1.06 & 3.54 & العلاقات الثكلية المكونة للعمل؟ & 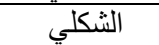 & 2 \\
\hline 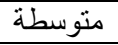 & 4 & 0.85 & 2.60 & المعنى العام للعمل وموضو عه & الموضوعي - ل المي & 3 \\
\hline
\end{tabular}

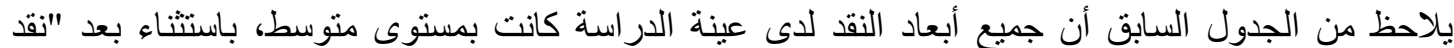

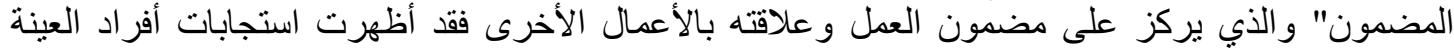

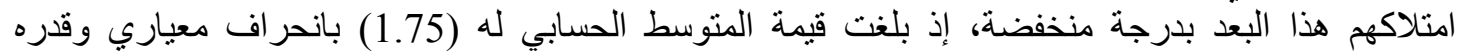

و أظهرت النتائج أن بعد "النقد الثكلي" حصل على أعلى منوسط حسابي لدى أفراد العينة، إذ بلغ (3.54) (3.43.

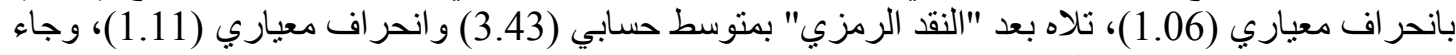

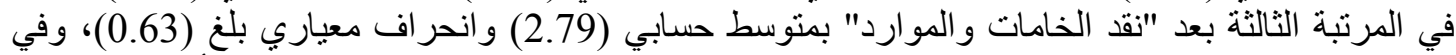

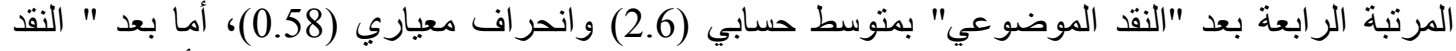

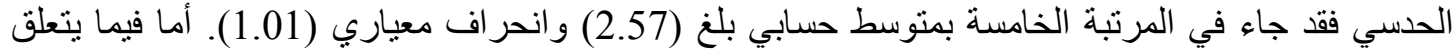
بالدرجة الكلية للمقياس فقد كانت الدرجة الدنيا (1) و الدرجة العليا (30) 


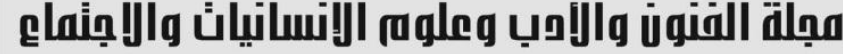

Journal of Arts, Literature, Humanities and Social Sciences www.jalhss.com

$$
\begin{aligned}
& \text { - - - تم تقسيم المقياس إلى ثلاث فئات: } \\
& \text { 1 - 1 (10.66) - 10.67) بدرجة ضعيفة. }
\end{aligned}
$$

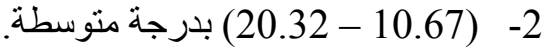

$$
\begin{aligned}
& \text { 3- - }
\end{aligned}
$$

فقد بلغ متوسط استجابات أفر اد عينة الدر اسة (16.68) بانحر اف معياري وقدره (5.1) و هذا يشير أيضا الى ألى

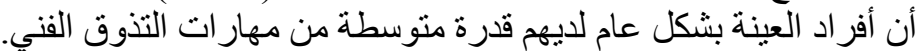

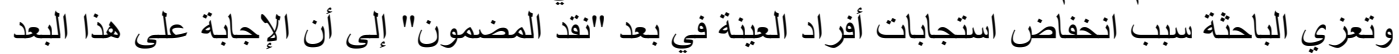

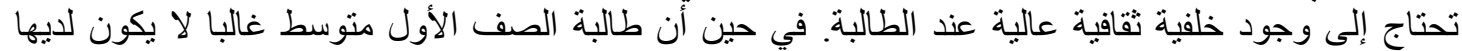

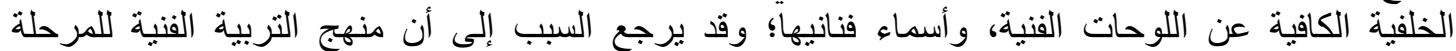

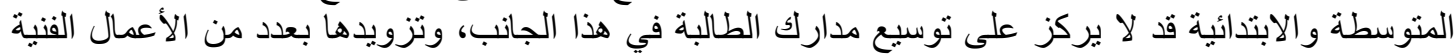

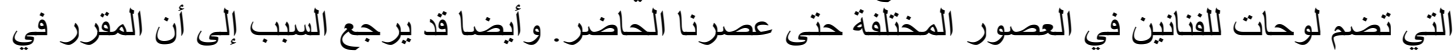

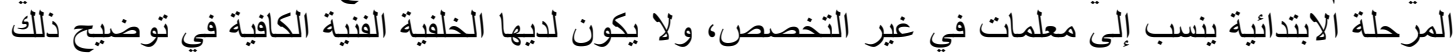

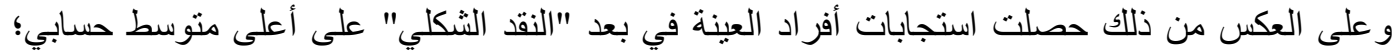

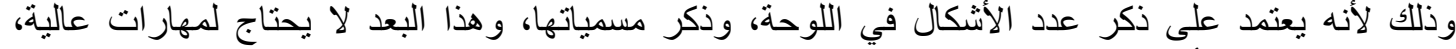

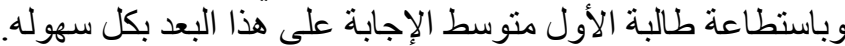

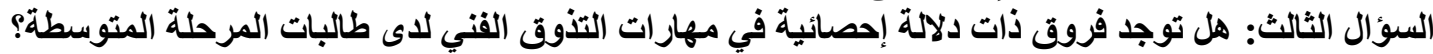

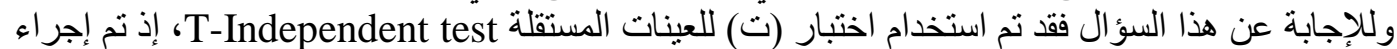
اختبار (ت) على بيانات العينة قبل إجراء التجربة لضمان تكافؤ العينتين كما يشير الجدول التالي:

\begin{tabular}{|c|c|c|c|c|c|}
\hline الإحصائية & قيمة اختبار T & الانحر اف المعياري & المتوسطي & المستقل & المتغير التابع \\
\hline \multirow{2}{*}{0.071} & \multirow{2}{*}{1.833} & 1.121 & 2.33 & مجمو عة 1 & \multirow{2}{*}{ النقد الحدسي } \\
\hline & & 1.064 & 2.81 & مجمو عة 2 & \\
\hline \multirow{2}{*}{0.096} & \multirow{2}{*}{1.688} & 1.042 & 3.33 & مجمو عة 1 & \multirow{2}{*}{ النقد الشكلي } \\
\hline & & 1.052 & 3.75 & مجمو عة 2 & \\
\hline \multirow{2}{*}{0.128} & \multirow{2}{*}{1.539} & 0.843 & 2.44 & مجمو عة 1 & \multirow{2}{*}{ 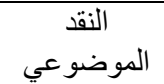 } \\
\hline & & 0.841 & 2.75 & مجموعة 2 & \\
\hline \multirow{2}{*}{0.343} & \multirow{2}{*}{0.954} & 1.117 & 3.31 & مجموعة 1 & \multirow{2}{*}{ النقد الرمزي } \\
\hline & & 1.107 & 3.56 & مجمو عة 2 & \\
\hline \multirow{2}{*}{0.091} & \multirow{2}{*}{1.716} & 0.632 & 2.67 & مجمو عة 1 & \multirow{2}{*}{ نق الخوادات } \\
\hline & & 0.604 & 2.92 & مجموعة 2 & \\
\hline \multirow{2}{*}{0.077} & \multirow{2}{*}{1.794} & 0.770 & 1.58 & مجمو عة 1 & \multirow{2}{*}{ نقد المضمون } \\
\hline & & 0.806 & 1.92 & مجموعة 2 & \\
\hline \multirow{2}{*}{0.092} & \multirow{2}{*}{1.708} & 5.060 & 15.67 & مجموعة 1 & \multirow{2}{*}{ الدرجة الكلية } \\
\hline & & 5.013 & 17.69 & مجموعة 2 & \\
\hline
\end{tabular}

جدول (8): اختبار ت للعينات المستقلة للكثف عن تكافؤ عينات الاراسة قبل إجراء التجربة

يشير الجدول السابق إلى أن قيمة اختبار (T) لأبعاد النقد الستة (الحدسي، الثكلي، الموضوعي، الرمزي،

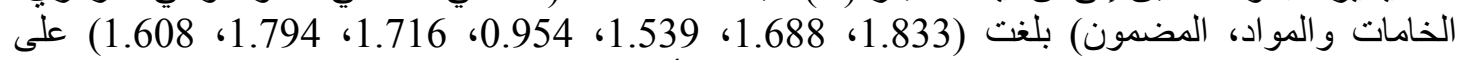
الترتيب وجميع هذه القيم لم تكن دالة إحصائيا مما يشير إلى أن المجمو عتين متكافئتين و لا يوجد بئن بينهما فروق في مهار ات التذوق الفني قبل تطبيق طريقة نقد آليت آيزنر.

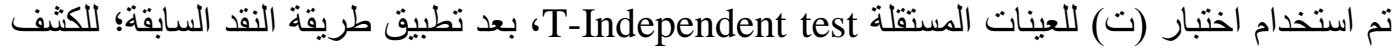
عن الفروقات التي تعزى لمتغير طريقة التدريس (التقليدية، آليت آيزنر)، كما يشير الجدول التالي: بلئ 


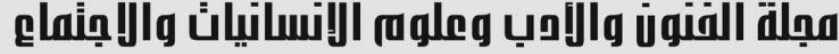

Journal of Arts, Literature, Humanities and Social Sciences www.jalhss.com

Volume (75) January 2022

العدد ( 2022 العاير

جدول (9): اختبار ت للعينات المستقلة للكثف عن الفروقات بين المجموعتين بعد تطبيق طريقة نقد آليت

آيزنر الفروقات

\begin{tabular}{|c|c|c|c|c|c|}
\hline الدلالة الإحصائية & قيمة اختبارT & الانحراف المعياري & المتوسط الحسابي & المتغير المستقل & المتغير التابع \\
\hline \multirow{2}{*}{0.000} & \multirow{2}{*}{3.805} & 1.229 & 2.44 & الضابطة & \multirow{2}{*}{ النقد الحسسي } \\
\hline & & 0.577 & 3.31 & التجرييية & \\
\hline \multirow{2}{*}{0.000} & \multirow{2}{*}{3.748} & 1.076 & 3.39 & الضابطة & \multirow{2}{*}{ النقد الثكلي } \\
\hline & & 0.710 & 4.19 & التجرييية & \\
\hline \multirow{2}{*}{0.000} & \multirow{2}{*}{3.760} & 0.845 & 2.53 & الضابطة & \multirow{2}{*}{ النق الموضوعي } \\
\hline & & 0.487 & 3.14 & التجريبية & \\
\hline \multirow{2}{*}{20.00} & \multirow{2}{*}{3.220} & 1.069 & 3.33 & الضابطة & \multirow{2}{*}{ النقد الرمزي } \\
\hline & & 0.632 & 4.00 & التجريبية & \\
\hline \multirow{2}{*}{20.00} & \multirow{2}{*}{3.171} & 0.649 & 2.75 & الضابطة & \multirow{2}{*}{ نق الخوادات } \\
\hline & & 0.447 & 3.17 & التجرييية & \\
\hline \multirow{2}{*}{0.000} & \multirow{2}{*}{6.867} & 0.878 & 1.83 & |الضابطة & \multirow{2}{*}{ نقد المضمون } \\
\hline & & 0.649 & 3.08 & التجرييية & \\
\hline \multirow{2}{*}{0.000} & \multirow{2}{*}{4.951} & 4.995 & 16.28 & الضابطة & \multirow{2}{*}{ الدرجة الكلية } \\
\hline & & 2.505 & 20.89 & التجريبية & \\
\hline
\end{tabular}

يشير الجدول السابق إلى أن قيمة اختبار (T) لأبعاد النقد الستة (الحسي، الثكلي، الموضوعي، الرمزي،

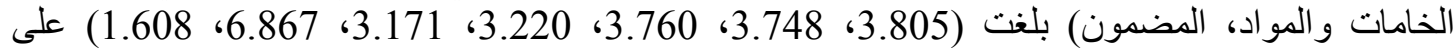
الترتيب، وجميع هذه القيم دالة إحصائيا؛ مما يشير إلى أن هنالك فروق في مهار اتل التئ التذوق الفني بين المجمو عتنين

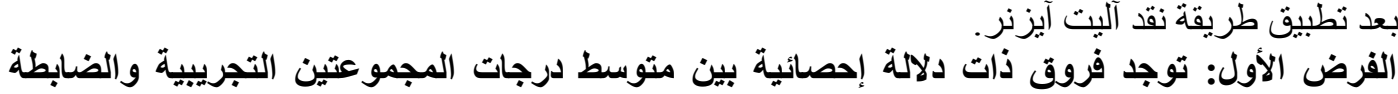

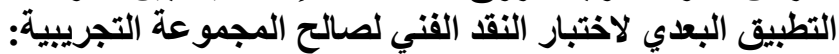

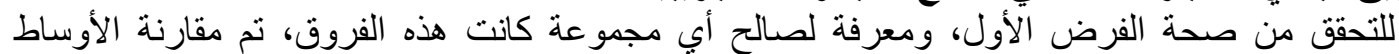

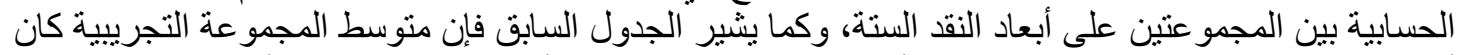

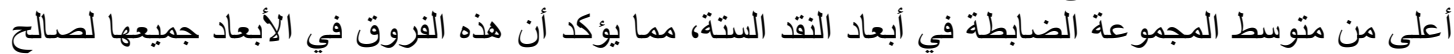
المجموعة التجرييية، أي أن تدريس الطالبات بطريقة آليت آيزنر كان له أثر دال إحصائيا على تنمية مهارات التيات

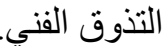

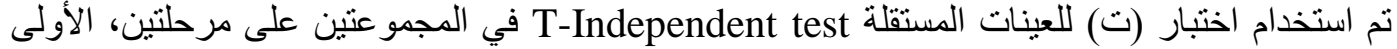

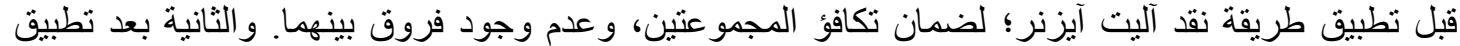
طريقة نقد آليت آيزنر؛ لفحص أثر التدريس وفق طريقة آليت آيزنر في اكتساب الطالبات لمهار ات التذان التوق الفني

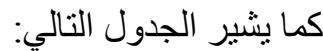

جدول (10) اختبار ت للعينات المستقلة للمجموعتين التجريبية والضابطة

\begin{tabular}{|c|c|c|c|c|c|c|}
\hline الإحصائية & قاختيمة & المعياري & الحسابي & المتغير المستقل & المتغير التابع & التطبيق \\
\hline \multirow{2}{*}{0.092} & \multirow{2}{*}{1.708} & 5. & 15. & و عة الضـابطة & \multirow{2}{*}{ على الاستنبيان } & \multirow{2}{*}{ قبل التطبيق } \\
\hline & & & 17.69 & 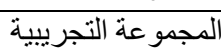 & & \\
\hline \multirow[t]{2}{*}{0.000} & \multirow[t]{2}{*}{4.951} & 4.9 & & جموعة الضـابطة & \multirow{2}{*}{ الدرجة الكلية } & \multirow{2}{*}{ بعد التطبيق } \\
\hline & & & & حمو عة التحر بينة & & \\
\hline
\end{tabular}

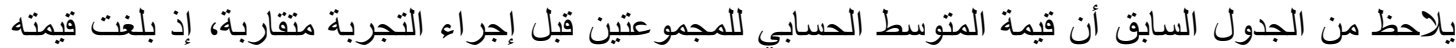

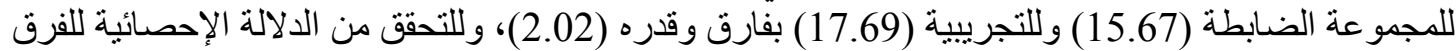
بين المتوسطين تم إجر اء اختبار (ت) و الذي بلغت قيمته (1.708) بمستوى دلالة وقدره (0.092) مما يؤكد عدم 


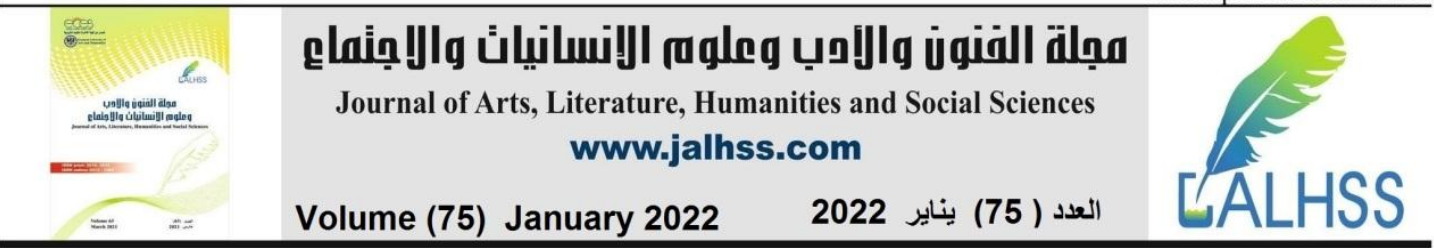

وجود دلالة إحصائية لهذا الفرق، أي أن المنوسط الحسابي لكلا المجموعتين قبل تطبيق طريقة نقد آليت آيزنر

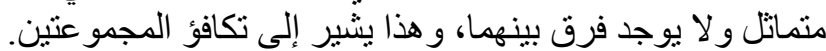

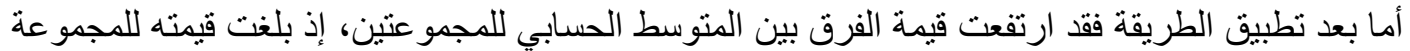

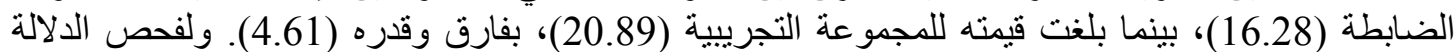

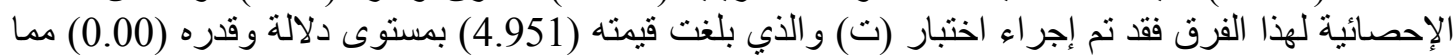

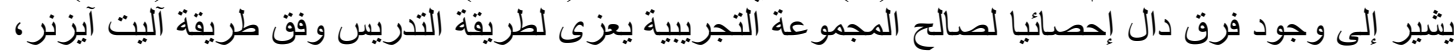

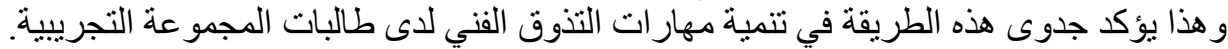

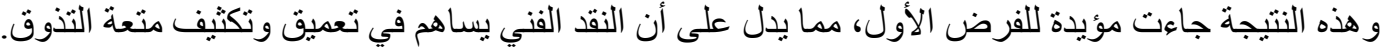

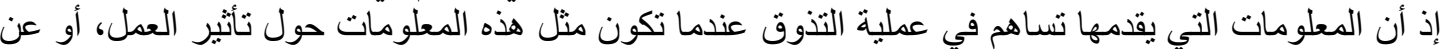

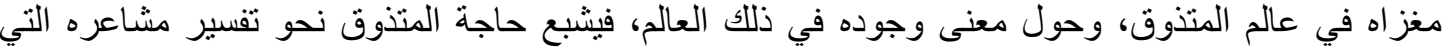

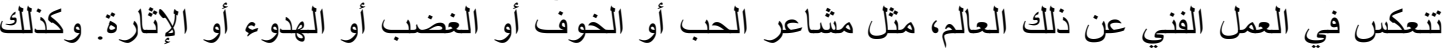

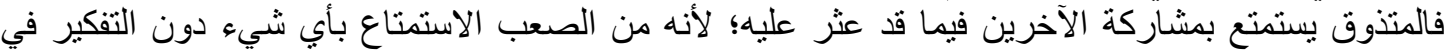

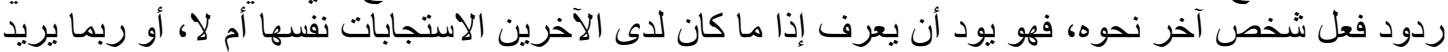

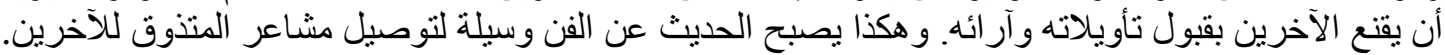

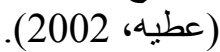
الفرض الثاني: توجد فروق ذات دلالة إحصائية بين متوسط درجات المجموعة التجريبية في التطبيق القبلي

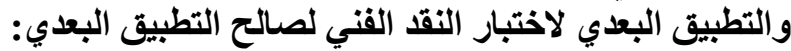

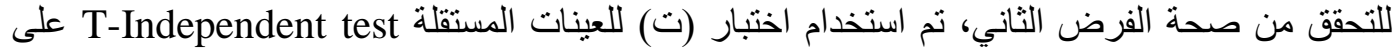
المجموعة التجرييية قبل تطبيق طريقة آليت آيزنر وبعدها؛ وذللك لفحص أثر التدريس وفق طريقة آليت آليت آيزنر في اكتساب الطالبات لمهار ات التذوق الفني كما يشير الجدول التالي:

جدول (11) اختبار ت للعينات المستقلة للمجموعتين التجريبية

\begin{tabular}{|c|c|c|c|c|c|c|}
\hline الإحصائية & |ختبار & الالمعراف & الحستوسطي & التطبيق & المستقلي & المتغير التابع \\
\hline \multirow{2}{*}{000.0} & \multirow{2}{*}{672.3} & 5.013 & 17.69 & قبل التجربة & \multirow{2}{*}{ التجرييية } & \multirow{2}{*}{ على الدقياس الكلية } \\
\hline & & 2.505 & 20.89 & التجربة & & \\
\hline
\end{tabular}

يلاحظ من الجدول السابق أن قيمة المتوسط الحسابي للمجموعة التجريبية قبل إجراء التجربة (17.69)، ألتوبة أما

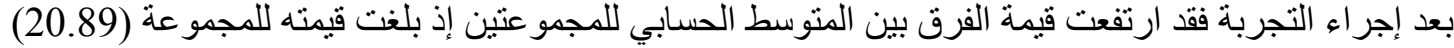

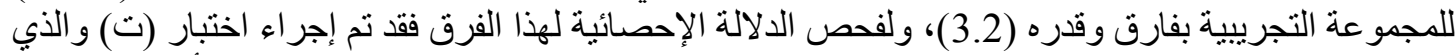

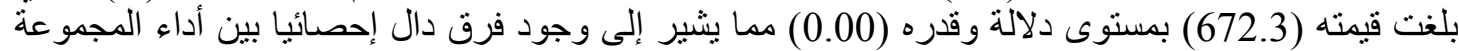
قبل وبعد تطبيق طريقة آليت آيزنر يعزى دلائ لطريقة التدريس.

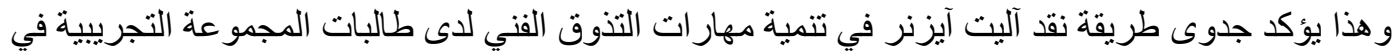

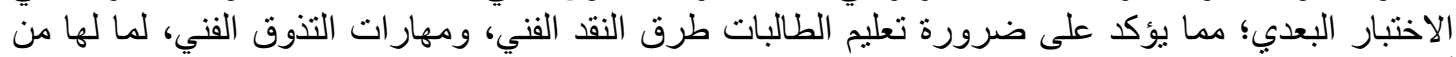

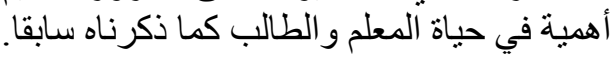

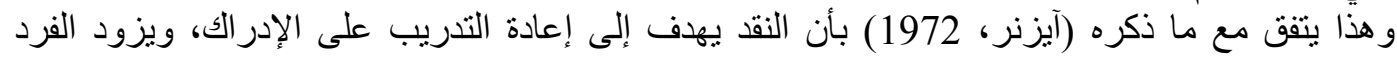
بأدو ات تجعله يشير إلى زو ايا مختلفة من مكونات العمل الفني، تؤدي إلى الإدر الك و الفهم لمحتوياته (عبدالكريم، الإدي، . (2016

كما يتفق مع دراسة (لبد، 2010) من حيث أن التذوق الفني هو مجموعة من المهارات التي يجب أن يمتلكها

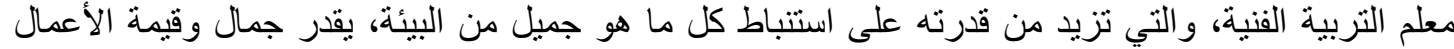

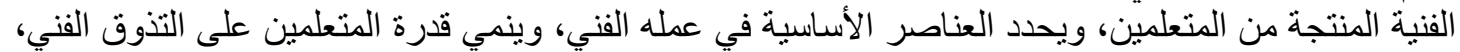

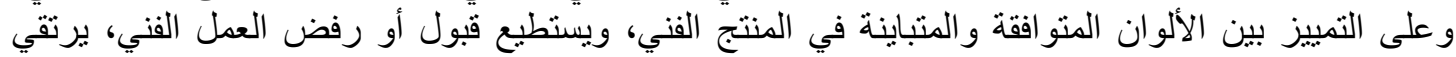
بمستوى الإحساس الفني، يفهم العلاقات الجميلة في المنتج الفني للمتعلمين. 


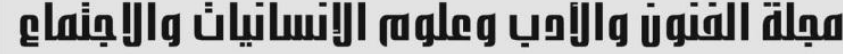

Journal of Arts, Literature, Humanities and Social Sciences www.jalhss.com

Volume (75) January 2022

العدد ( 75) يناير 2022

\section{التوصيـــــات:}

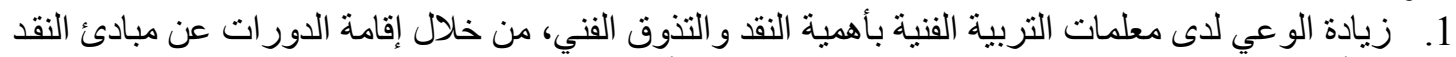

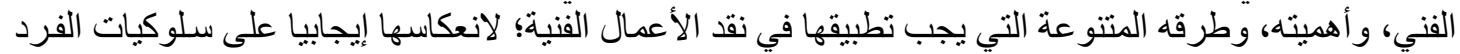
في المجتمع. 2. إعـادة صـياغة المو اقف التعليميـة مـن الثكل التقليدي، إلى شكل جديــ بمثل فيـه الطالبـات محوراً للعمليـة

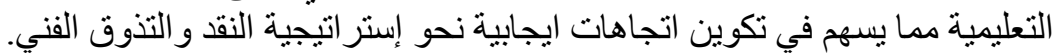

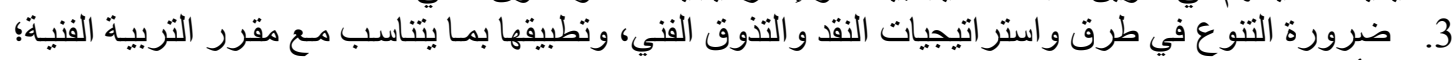

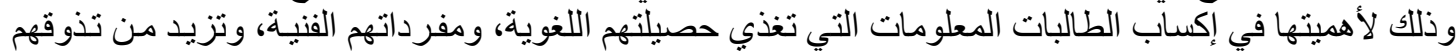
بشكل أفضل، ولمدة أطول.

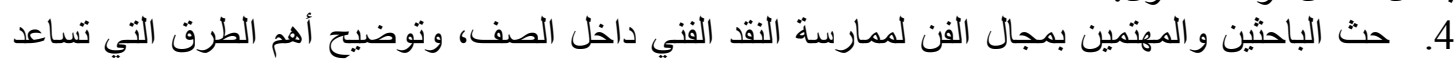

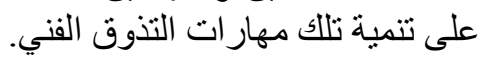

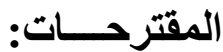
口 إجراء المزيد مـن الدراسات حول البرامج التعليمية في مجال النقد الفني في التربية الفنية على طلاب وطالبات المر احل الدر اسية المختلفة، و على طلاب وطالبات الكليات قسم التربية الفنية. إجر اء در اسة لمعرفة المعوقات التي تواجه معلمات التربية الفنية وتحد من ممارستهم للنقد الفني التعليمي لتهي الخاتم

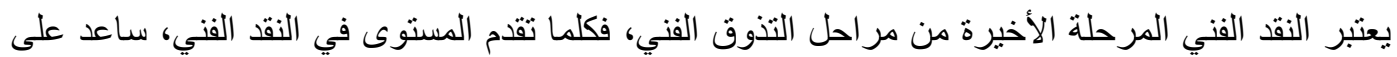

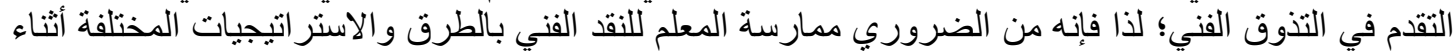

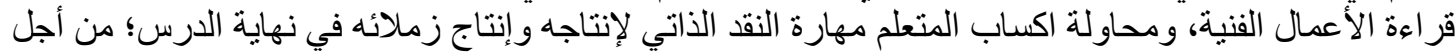

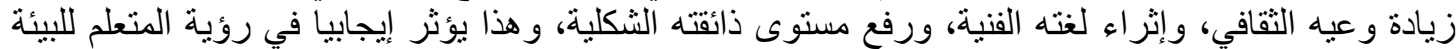

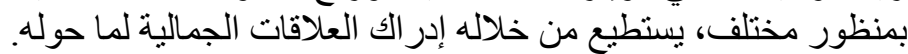

1. ملبوش، مشيرة مطاوع ع. (2001م). البحث الجمالي لتنمية القدرة على التفكير الناقد في التربية الفنية وقياس

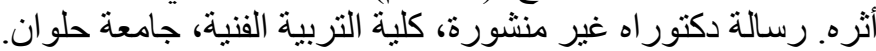

2.

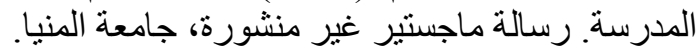

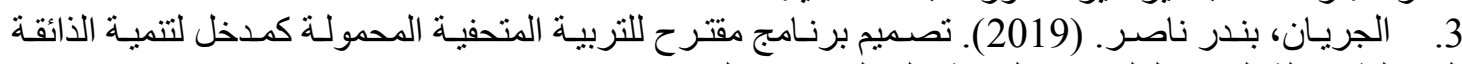

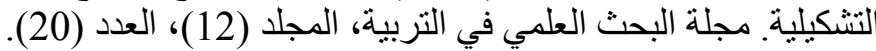

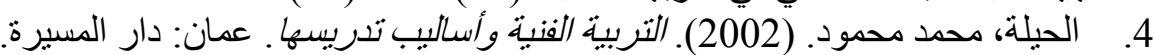

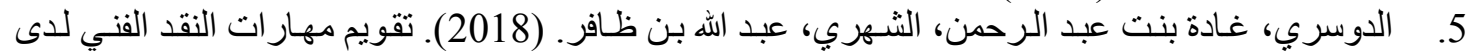
معلمات التربية الفنية وتدريسهن لها في المرحلة المتوسطة في مدينة الريـاض. المجلة الدوليـة للار اسـات التربويـة

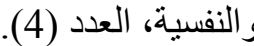
6. دياب، عبير صبحي. (1999). برنامج مقترح للتربية المتحفية كمدخل للتذوف الفني للطفل. رسالة ماجستير غير منشورة، كلية التربية الفنية، جامعة حلو انوان.

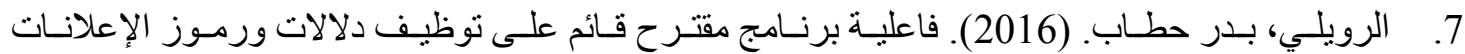
التلفزيونية لتنمية مهارة النقد الفني باستخدام طريقة تشارلز بيرس لعينة من طلاب الصف التفان الثاني متوسط في مقرر

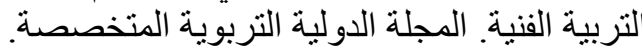
8. 9. الزهر اني، عبد الرحمن. (2008). أسباب عزوف علير معلمي التربية الفنية بمدينة الطائف التعليمية عن استخدام

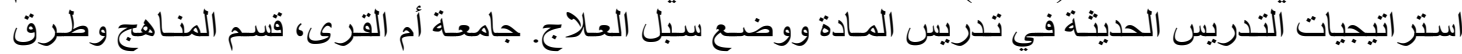




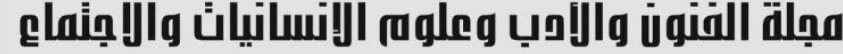

Journal of Arts, Literature, Humanities and Social Sciences www.jalhss.com

Volume (75) January 2022

العدد ( 2022 العناير

10. ستولنر، جيروم. (1992). النقد الفني دراسة جمالبة. نرجمة: فؤاد زكريـا. الإسكندرية: دار الوفاء للطباعة

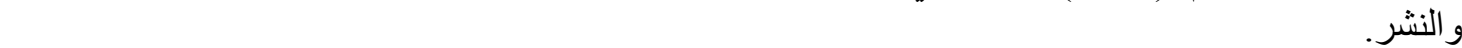
11. الضويحي، محد حسين. (2003). نظرية التربية الفنبـة المبنية على الفن بوصفية مـادة در اسبة و إمكانيات

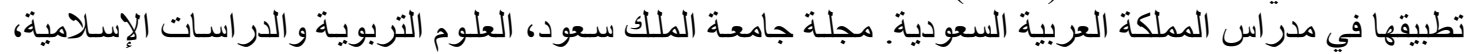

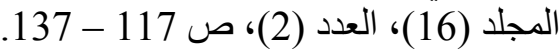

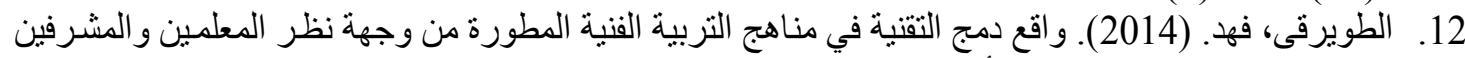
التربو يين بمنطقة مكة المكرمة. جامعة أم القرى، قسم التربية الفية الفنية.

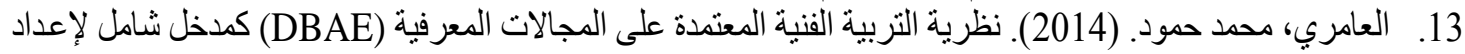
معلم الفن بجامعة السلطان قابوس. مجلة العلوم التربوية، العدد (4)، المجلد (1200لة (1).

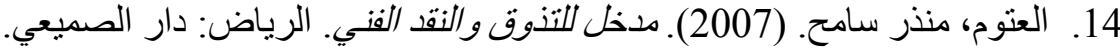

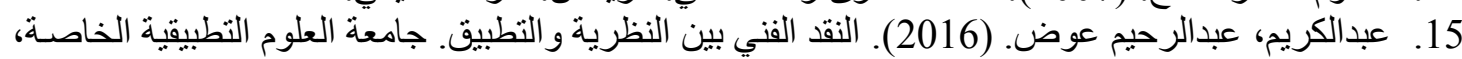
كلية الفنون و التصميم، الأردن.

16. عطيه، محسن محمد. (1902). النقا الفنون من الككاسيكية البى عصر ما بعد الحداثة. الإسكندرية: منشأة المعارف. 17. الغامدي، أحمد. (1999). دور النقد الفني في إنماء الثقافة الفنية. رسالة ماجستير غير الإنير منشورة، كلية التربية،

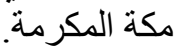

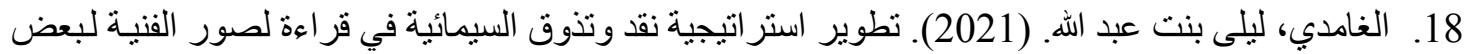

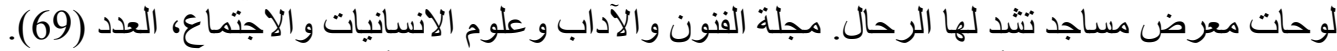

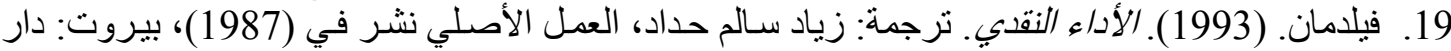
المناهل.

20. قزاز، ، طارق بكر ـ (2002م). طبيعة النقد الفني المعاصر في الصحافة السعودية. رسالة ماجستير ، جامعة أم

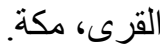

21. لبد، عبدالكريم محمد. (2010). الكفايات الأساسية لدى معلمي التربية الفنية و علاقتها بالتذوق الفني في الإنية

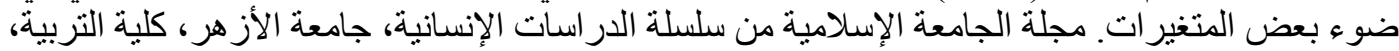

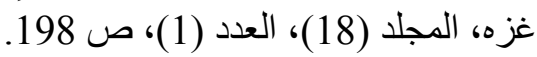

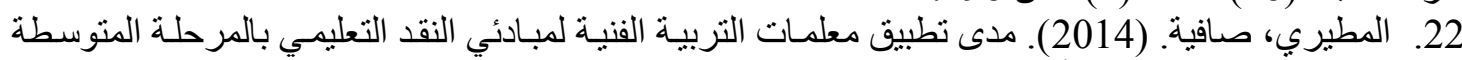

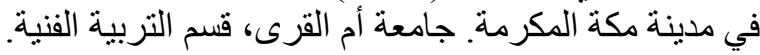

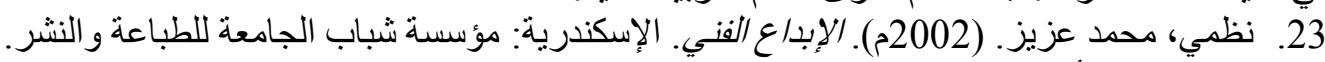
24. هيكل، محمد أبو المعاطي. (2004م). محاضرات في النقد والتذوق الفني. كلية التربية الفنية، جامعة حلوان، 25. وزارة التعليم. (2016). التربية الفنبة للصف الأول المتوسط ـ دلبل المعلم. الرياض: العبيكان للطباعة. 26. Barkan, M., Chapman, L. \& Others. (1970). Guide Lines, Curriculum Development for Aesthetic Education. Missouri; Central, INC.

27. Duh, M., \& Korosec Bowen, A. (2014). The development of art appreciation abilities of pupils in primary school. The new educational review, Volume (35), No. (2). pp. 42-55.

28. Rosenthal, Yadin. (1996). Dictionary of progress philosophy. nscom, press, London.

29. https://www.minia.edu.eg/kind/files/abda3fan.pdf.

30. المعري، بدر. (2013). نقد الفن التشكيلي: الجانب المظلم للمبالغة والتشويق، مقال منشور file:///C:/Users/welcome/AppData/Local/Temp/ResearchGate2.pdf. 31. الاطرقجي، ثائر شاكر. (2011). مدونة تهتم بأدبيات الخط العربي. http://alatraqchi.blogspot.com/2011/01/blog-post_06.html. 


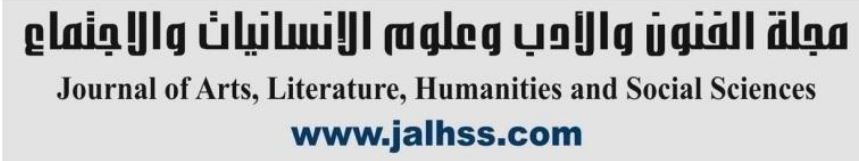

Volume (75) January 2022

العدد ( 75) يناير 2022

\section{References}

1. Balboush, Mushira Mutawa. (2001). Aesthetic research to develop the ability to critical thinking in the art education and measuring its impact. Ph.D. thesis unpublished, The Art Education Faculty, Helwan University.

2. Al-Banna, Ahmed Ibrahim. (1992). The effect of using art education as an approach to develop the religious feeling among a pre-school child, unpublished master's thesis. Minia University.

3. Al-Jeryan, Bandar Nasser. (2019). Designing a proposed program for portable museum education as an entry point for developing the fine taste. Journal of Scientific Research in Education, Volume (12). No. (20).

4. Al-Hilah, Mohamed Mahmoud. (2002). The Art Education and its Teaching Methods. Amman: Dar Al-Masira.

5. Al-Dosari, Ghada bint Abdul Rahman, Al-Shehri, Abdullah bin Dhafer. (2018). Evaluation of Art Criticism Skills for Art Education Teachers and Teaching them in the Intermediate Stage in Riyadh. International Journal of Educational and Psychological Studies, No. (4).

6. Diab, Abeer Sobhi. (1999). The effectiveness of a proposed program for museum education as an approach to the child's artistic perception. unpublished master's thesis, Faculty of Art Education, Helwan University.

7. Al-Ruwaili, Badr Hattab. (2016). The effectiveness of a proposed program based on employing the indices and symbols of television advertisements to develop the skill of art criticism using the Charles Pierce method for a sample of second-grade intermediate students in the art education course. the Specialized International Educational Journal.

8. Al-Zayer, Saleh. (2014). unpublished presentation.

9. Al-Zahrani, Abdul Rahman. (2008). Reasons for the Reluctance of Art Education Teachers in Taif Educational City to Use Modern Teaching Strategies in Teaching Subject and Developing Treatment Methods. Umm Al-Qura University, Department of Curricula and Teaching Methods.

10. Stolner, Jerome. (1992). Art criticism is an aesthetic study. Translation: Fouad Zakaria. Alexandria: Dar Al-Wafaa for Printing and Publishing.

11. Al-Duwaihi, Mohamed Hussain. (2003). Theory of Art Education based on Art as a Subject and the Possibilities of Its Application in the Schools of the Kingdom of Saudi Arabia. Journal of King Saud University, Educational Sciences and Islamic Studies, Volume (16). No. (2). pp. 117-137.

12. Al-Tuwairqi, Fahd. (2014). The reality of integrating technology into the developed art education curricula from the point of view of teachers and educational supervisors in the Makkah region. Umm Al Qura University, Art Education Department.

13. Al-Amri, Mohamed Hamoud. (2014). Knowledge-based Art Education Theory (DBAE) as a comprehensive approach to preparing an art teacher at Sultan Qaboos University. Journal of Educational Sciences, Volume (1), No. (4).

14. Al-Atoum, Munther Sameh. (2007). An approach to appreciation and art criticism. Riyadh: Dar AlSumaei. 


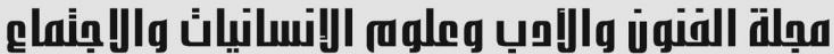 \\ Journal of Arts, Literature, Humanities and Social Sciences www.jalhss.com \\ Volume (75) January 2022 \\ العدد ( 75) يناير 2022}

15. Abdel Karim, Abdel Rahim Awad. (2016). Art criticism between theory and practice. Applied Science Private University, College of Art and Design. Jordan.

16. Attia, Mohsen Mohamed. (2002). Art Criticism from Classical to Postmodern Era. Alexandria: Al-Ma'aref building.

17. Al-Ghamdi, Ahmed. (1999). The Role of Art Criticism in Developing Artistic Culture. Unpublished Master's Thesis, College of Education, Makkah AlMukarramah.

18. Al-Ghamdi, Laila bint Abdullah. (2021). Developing a strategy of criticism and appreciating semiotics in a reading of artistic images of some mosques exhibition paintings that are visited. Journal of Arts, thesis, Humanities and Sociology, No. (69).

19. Feldman. (1993). Monetary performance. Translation: Ziyad Salem Haddad. the original work was published in (1987). Beirut: Dar Al-Manahil.

20. Qazzaz, Tariq Bakr. (2002). The Nature of Contemporary Art Criticism in the Saudi Press, Master's Thesis. Umm Al Qura University, Mecca.

21. Lubbed, Abdul Karim Mohamed. (2010). The basic competencies of art education teachers and their relationship to art appreciation in the light of some variables. The Journal of the Islamic University from the Human Studies Series, Al-Azhar University, College of Education, Gaza, Volume (18), No. (1). p. 198.

22. Al-Mutairi, Safia. (2014). The extent to which art education teachers apply the educational criticism principles in the intermediate stage in Makkah Al-Mukarramah city. Umm Al Qura University, Art Education Department.

23. Nazmi, Mohamed Aziz. (2002). Artistic Creativity. Alexandria: University Youth Foundation for Printing and Publishing.

24. Heikal, Mohamed Abu Al-Maati. (2004). Lectures on criticism and artistic appreciation. Faculty of Art Education, Helwan University, Egypt.

25. Ministry of Education. (2016). Art Education for the First Intermediate Class Teacher's Guide. Riyadh: Obeikan for printing.

26. Barkan, M., Chapman, L. \& Others. (1970). Guide Lines, Curriculum Development for Aesthetic Education. Missouri; Central, INC.

27. Duh, M., \& Korosec Bowen, A. (2014). The development of art appreciation abilities of pupils in primary school. The new educational review, Volume (35), No. (2). pp. 42-55.

28. Rosenthal, Yadin. (1996). Dictionary of progress philosophy. nscom, press, London.

29. https://www.minia.edu.eg/kind/files/abda3fan.pdf.

30. Al-Maamari, Badr. (2013). Criticism of fine art: the dark side of exaggeration and suspense. published article.

file://C:/Users/welcome/AppData/Local/Temp/ResearchGate2.pdf.

31. Al-Atrakji, Thaeir Shaker. (2011). Blog interested in the literature of Arabic calligraphy.

http://alatraqchi.blogspot.com/2011/01/blog-post_06.html. 